\title{
New Insights into North European and North Atlantic Surface Pressure Variability, Storminess, and Related Climatic Change since 1830
}

\author{
Edward Hanna,* John Cappelen, ${ }^{+}$Rob Allan, ${ }^{\#}$ Trausti Jónsson, ${ }^{@}$ Frank Le BlancQ, $\&$ \\ Tim Lillington, $* *++$ AND KiERAN Hickey \#\# \\ * Department of Geography, University of Sheffield, Sheffield, United Kingdom \\ + Danish Meteorological Institute, Copenhagen, Denmark \\ \# Met Office Hadley Centre, Exeter, United Kingdom \\ @ Icelandic Meteorological Office, Reykjavík, Iceland \\ \& Jersey Meteorological Department, Saint Helier, Jersey \\ ** Guernsey Meteorological Office, Saint Peter Port, Guernsey \\ \#\# Department of Geography, National University of Ireland, Galway, Ireland
}

(Manuscript received 22 October 2007, in final form 11 April 2008)

\begin{abstract}
The authors present initial results of a new pan-European and international storminess since 1800 as interpreted from European and North Atlantic barometric pressure variability (SENABAR) project. This first stage analyzes results of a new daily pressure variability index, $\mathrm{dp}(\mathrm{abs}) 24$, from long-running meteorological stations in Denmark, the Faroe Islands, Greenland, Iceland, the United Kingdom, and Ireland, some with data from as far back as the 1830s. It is shown that dp(abs)24 is significantly related to wind speed and is therefore a good measure of Atlantic and Northwest European storminess and climatic variations. The authors investigate the temporal and spatial consistency of $\mathrm{dp}(\mathrm{abs}) 24$, the connection between annual and seasonal dp(abs)24 and the North Atlantic Oscillation Index (NAOI), as well as dp(abs)24 links with historical storm records. The results show periods of relatively high dp(abs) 24 and enhanced storminess around 1900 and the early to mid-1990s, and a relatively quiescent period from about 1930 to the early 1960s, in keeping with earlier studies. There is little evidence that the mid- to late nineteenth century was less stormy than the present, and there is no sign of a sustained enhanced storminess signal associated with "global warming." The results mark the first step of a project intending to improve on earlier work by linking barometric pressure data from a wide network of stations with new gridded pressure and reanalysis datasets, GCMs, and the NAOI. This work aims to provide much improved spatial and temporal coverage of changes in European, Atlantic, and global storminess.
\end{abstract}

\section{Introduction}

The location and intensity of the midlatitude storms are major influences on the climate of Europe. However, many potential variables for assessing storm climate (e.g., wind speed) are too short term and/or beset with severe inhomogeneities to be of great use (von Storch and Weisse 2008). For the Northern Hemisphere, atmospheric pressure data throughout the troposphere on a subdaily basis currently exist in the form

++ Retired.

Corresponding author address: Edward Hanna, Department of Geography, University of Sheffield, Winter Street, Sheffield S10 2TN, United Kingdom.

E-mail: ehanna@sheffield.ac.uk of National Centers for Environmental PredictionNational Center for Atmospheric Research (NCEPNCAR) reanalysis data from 1948 to present (Kistler et al. 2001) and the 40-yr European Centre for MediumRange Weather Forecasts (ECMWF) reanalysis (ERA40) from 1957-2001 (Uppala et al. 2005). These reanalyses allow the use of cyclone detection and tracking algorithms to derive the frequency and intensity of individual storm systems. From these data, a decrease in midlatitude cyclone activity and an increase in highlatitude cyclone activity have been identified (Wang et al. 2006; McCabe et al. 2001), indicating a poleward shift in storm-track location (Trenberth et al. 2007). However, these analyses are subject to uncertainty in the reanalysis data (Bromirski et al. 2003; Chang and Fu 2002; Smits et al. 2005). As a result of changing data density, cyclone-tracking algorithms cannot provide ho- 
mogeneous long-term information. Furthermore, they do not provide specific information on atmospheric pressure fluctuations on spatial and temporal scales from local to global and from subhourly to monthly. Because such pressure fluctuations are a more continuous measure of atmospheric dynamics, they are likely to provide a unique and complementary record of changes in storminess. In addition, they should give more detailed insight into general variations in surfacepressure systems (anticyclones as well as depressions), which are also often related to changes in mid- to upper-air circulation and particularly jet streams-the main forcing agent of deep depressions and hence storminess.

Prior to the reanalysis period, station pressure measurements have been the only viable tool for determining storm-track and atmospheric circulation variability: these records are longest and most widespread in the North Atlantic-European sector. Alexandersson et al. $(1998,2000)$ and Matulla et al. (2007) used daily pressure readings to calculate 99th-percentile values of the geostrophic wind for several triangles of stations in northern Europe from about 1880 and in central Europe from the 1870s. Bärring and von Storch (2004) analyzed annual numbers of deep pressure systems and exceedance counts of 12-h pressure tendencies from about 1800 for two Swedish stations. These studies identified high storminess in the late nineteenth century, a minimum around 1960, and a subsequent increase until around 1990 (Trenberth et al. 2007). Allan et al. (2008, hereafter AL08) built on the study by Alexander et al. (2005) by using 3-hourly pressure tendencies from a number of stations across the British Isles to extend a severe storminess analysis in that region back to 1920. In AL08 a common peak in severe storminess was found in autumn and winter during the 1990s, but they also detected a strong peak in the 1920s that was dominant over the 1990s maxima in autumn. However, these studies are spatially or temporally restricted, making their wider climatic interpretation difficult.

Until recently, the North Atlantic Oscillation Index (NAOI; based on pressure measurements in Iceland and either the Azores or Iberia) was the only means of inferring the atmospheric circulation over the northwest European-North Atlantic region prior to the period of more plentiful observations (e.g., Hurrell 1995; Jones et al. 1997). There are apparent links between the North Atlantic Oscillation (NAO) and the northwest European storminess for the past $150 \mathrm{yr}$ (e.g., Dawson et al. 2004). However, as with all statistical indices, the NAOI is a $1 \mathrm{D}$ representation of what is in reality a complex 4D dynamical atmospheric process. Thus the NAOI is sensitive to (i) early barometric index errors (e.g., Jones et al. 2003; Vinther et al. 2003) and (ii) migration of the bipolar centers of action under different climatic regimes, yet-as pointed out by Jónsson and Hanna (2007) - the index is often used uncritically by climate (and many other) researchers.

Jónsson and Hanna (2007) have recently applied a pressure-variability index, the $\operatorname{dp}(\mathrm{abs}) 24$, which is the absolute 24-hourly atmospheric surface pressure variation at a location. The dp(abs)24 index, therefore, has both spatial and temporal variability and is an effective 4D proxy for atmospheric variability or storminess (Jónsson and Hanna 2007). This technique has been largely overlooked by modern climatologists, although it is often discussed in old and now largely ignored climatological literature (see Lamb 1972, 272-273, and references therein). However, research on this topic goes back to the early nineteenth century. The first person to introduce daily pressure variability as a concept seems to have been Kämtz (1832) in Landsberg (1966) in a textbook on meteorology. In an analysis of the Reykjavík pressure measurements made during 1841-44, Pedersen (1845) calculated both the diurnal variation of pressure and the seasonal variation of $\mathrm{dp}(\mathrm{abs}) 24$; he concluded that $\mathrm{dp}(\mathrm{abs}) 24$ is "considerably larger than in our latitudes [i.e., Denmark and Germany compared with Iceland].” Bahr (1911), Berger (1961), and Landsberg (1966) studied dp(abs) 24 for several-year periods in the early and mid-twentieth century. These and other early efforts were mainly concerned with the spatial rather than temporal pressure variability. However, Travnicek (1928) calculated the secular variability of dp(abs)24 at Saltzburg, Austria (1870 to 1926), and also at the high-elevation station Sonnblick, Austria, for 1887 to 1926 . He used these data to refute an assertion of Bahr (1911) that the 10-yr means of dp(abs) 24 are more or less constant throughout time for each location. Also, Evjen (1917, and references therein) calculated the secular change of a closely related parameter-the sum of the absolute differences between the three (then standard time) pressure observations per day and the first observation of the following day-in Vardö in northern Norway during 1871 to 1926 . He found a marked (downward) secular change, which he remarked corresponds with a marked decrease in storminess in northern Norway during the period up to 1917 that had already been reported in the Norwegian Journal Naturen (Evjen 1917).

Klein (1951) discussed differences between two related measures, namely, the (e.g., monthly) standard deviation of daily pressure variability, $\mathrm{dp}(\mathrm{std})$, and the (e.g., monthly) standard deviation of daily pressure, $\mathrm{p}(\mathrm{std})$, which are compared with dp(abs) 24 by Jónsson and Hanna (2007). The former index is considered to 
emphasize extreme pressure changes-rather than changes in the mean "storminess" climate-but merits further research alongside dp(abs)24, although both $\mathrm{dp}(\mathrm{std})$ and $\mathrm{dp}(\mathrm{abs}) 24$ show similar variations and secular changes when applied to the 1823-2005 southwest Iceland pressure series. On the other hand, $p(s t d)$ may not adequately distinguish between different weather regimes during the course of a month, so we were disinclined to use this index further (Jónsson and Hanna 2007). Klein (1951) also analyzed the one-day lag autocorrelation of pressure-another measure of the dayto-day pressure variability and one that reveals well the spatial patterns but seems to yield relatively little information concerning the all-important secular (seasonal/ interannual) fluctuations.

Lamb (1972) reported that the zone of maximum pressure variability closely mirrors the main subpolar cyclone zone, with the highest mean dp(abs)24 values of $\sim 11 \mathrm{hPa}$ in winter just off the Atlantic seaboard of Nova Scotia-Newfoundland and near East GreenlandIceland, reflecting sharp temperature contrasts and pressure changes in these regions; in summer, in accordance with generally much less stormy conditions, the zone of highest mean $\mathrm{dp}(\mathrm{abs}) 24$ was $>6 \mathrm{hPa}$ in the south of Hudson Bay. Spatial variability in dp(abs)24 can be depicted on weather maps by means of isallobars, meaning "lines of equal pressure change" (Dunlop 2001). Lamb (1972, p. 273) also offers the following characteristically prescient quote:

The fact that maximum interdiurnal variability of pressure [here dp(abs)24] is linked with the jet stream through the sequences of surface frontal cyclones travelling principally along its cold flank, makes it possible to use the average day-by-day changes of surface pressure in individual months or years to reveal variations in the proximity of the jet stream to this or that observing station (Bayer 1965). This seems to offer a method of reconstructing the position and course of the depression tracks, and thereby of the mainstream of the upper westerlies, in past years long before the establishment of an upper air observation network and possibly for the European sector back to the eighteenth century.

Indeed, Putins (1962) presents a pioneering statistical analysis and preliminary dynamical interpretation of the relationship between surface and upper-air (500 and $300 \mathrm{hPa}$ ) interdiurnal pressure changes over the Greenland area, but these findings, while extremely interesting, are limited by the regional coverage of their study and the lack of a modern atmospheric dynamics context. In a more recent background study, Flocchini and Palau (1987) analyze interdiurnal pressure variations at the University of Genoa (Italy) Observatory from 1833-1981; perhaps rather surprisingly, given their long record, the authors do not present-and indeed barely allude to-the secular time series of dp(abs)24 but instead state that its properties are very similar for the entire long period of observation.

Most recently, Schmith et al. (1998) used exceedance thresholds of the dp(abs)24 index as surrogates of northeast Atlantic storminess for 1875-1995: they found dominant interannual and decadal variability, despite an enhancement of the northeast section of the storm track during the final 20-30 yr. However, $\mathrm{dp}(\mathrm{abs}) 24$ has been relatively neglected by contemporary climatologists-perhaps partly due to its conceptual simplicity - in favor of the storm-track methods described above, so our paper aims to redress the balance.

Analyzing dp(abs)24 has several advantages. First, it is ripe for exploitation using much longer-running, more detailed, and homogenized barometric pressure series than were available to the early authors discussed above, which enables a much better overview of its seasonal and secular (long-term interannual to decadal to centennial) variations. Second, dp(abs) 24 can use either mean sea level or station-level pressure readings, so at least for low-level stations, it is not dependent on knowing station altitude nor on knowledge of instrument and other corrections, because such errors are effectively "constant errors" (Jónsson and Hanna 2007). Third, the dp(abs) 24 method makes good use of nineteenth-century pressure data: prior to about 1880 , barometric observations were sometimes only made once daily (or if made two or three times daily were not always evenly spaced or at fixed times) and pressures were usually at station level, so dp(abs)24 makes use of valuable data that might otherwise be unused or regarded as unusable. Jónsson and Hanna (2007) used this index to study long-term (multidecadal) changes in Icelandic surface atmospheric pressure variability and related (e.g., wind/storminess) climate change since 1823.

In this paper, we derive $d p(a b s) 24$ for a representative and well-distributed sample of long-running daily pressure data from stations across the northern North Atlantic and northwest European regions for the past $160 \mathrm{yr}$. This is intended to supplement the limited information on North Atlantic storminess and climate change available from the NAOI and other restricted results described above. Our analysis will therefore be particularly valuable for filling in the nineteenthcentury part of the period and for evaluating recent and ongoing climate change. Part of the problem with the NAOI is the inconsistency of its long-term relationships with other climatic parameters (e.g., Haylock et al. 2007; Polyakova et al. 2006; Rogers 1997; Zveryaev 


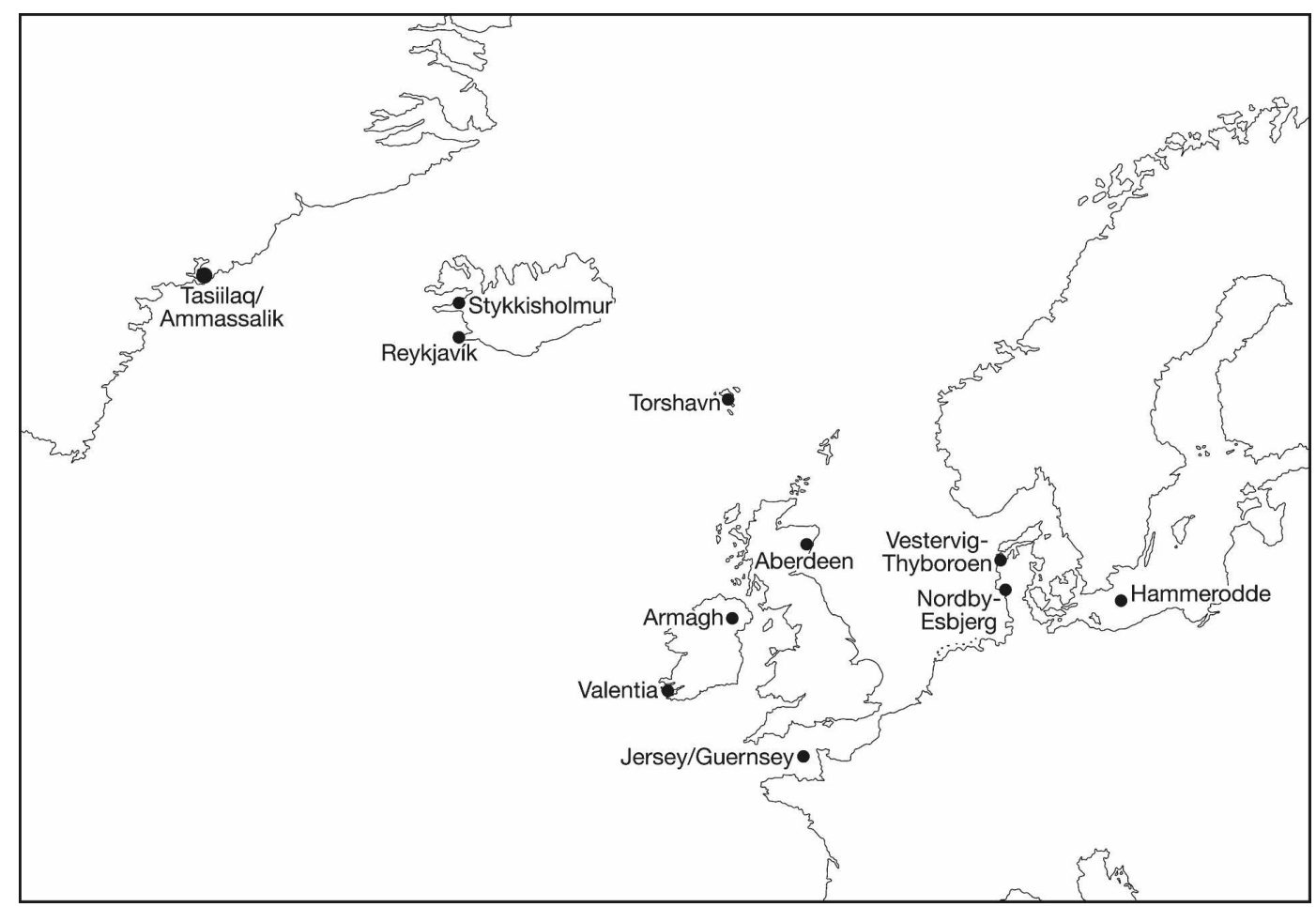

FIG. 1. Location map showing long-term barometric pressure stations used in this study.

1999). The relation between the temperature in northern Europe and the NAOI is a typical case: the two are highly correlated in recent decades, but the relationship is much more diffuse during some earlier periods (e.g., Jones et al. 2003; Jónsson and Hanna 2007). Also, variations in northern European storm frequency are only modestly correlated with variations in the NAOI (WASA Group 1998). These inconsistencies and diffuse relationships are most probably due to NAO centers of action changing with time-an aspect that requires closer attention (Kingston et al. 2006). Another strength of the dp(abs)24 is its ability to reveal climate as being spatially variable and not just made up of weather but periods of variable length (typically several days to weeks) with similar weather (e.g., blocked versus mobile patterns). We can therefore use dp(abs)24 as a new tool to quantify short-term (weekly to annual) synoptic variability, for example, to examine how and why the NAO disconnects from local surface-pressure patterns at different times and in different transatlantic places and to quantify longer-term climatic change.

\section{Climatological data}

\section{a. Barometric pressure datasets and quality control}

The research utilizes predigitized long-running (sub-) daily barometric pressure data from four stations in the United Kingdom (Aberdeen, Armagh and Jersey/ Guernsey), one in the Republic of Ireland (Valentia), three stations or nearby (10- to 13-km separation) pairs of stations in Denmark (Hammerodde, NordbyEsbjerg, and Vestervig-Thyboroen), Torshavn in the Faroe Islands, and Tasiilaq/Ammassalik in Greenland (Fig. 1). In addition, we make reference to the SW Iceland $\mathrm{dp}(\mathrm{abs}) 24$ series already published and analyzed by Jónsson and Hanna (2007). The bulk of the pressure data between around 1874 and 1995 for these stations, except Armagh and Jersey/Guernsey, were obtained from a Danish Meteorological Institute (DMI) technical report compilation of the European Union (EU)-funded Waves and Storms in the North Atlantic (WASA) project results (Schmith et al. 1997). Available updates, extensions, and infills were provided by DMI for stations in Denmark, the Faroe Islands, and Greenland-and subsequently published with relevant metadata in Cappelen et al. (2007) — and by the Met Office Hadley Centre for Aberdeen and Valentia. The (sub)daily pressure data were updated, wherever possible until the end of 2006 (September 2007 for DMI data).

The Armagh barometric pressure series was obtained from the Armagh Observatory (Northern Ireland; see de Groot (1994) for background) and extends from 1795 to the present, although because of issues with 
TABLE 1. Location, height, period, and source of barometric pressure stations used in this study.

\begin{tabular}{|c|c|c|c|c|c|}
\hline Station & Lat & Lon & $\begin{array}{l}\text { Station height } \\
\text { MSL }(\mathrm{m})\end{array}$ & Period(s) & Source \\
\hline Jersey, Channel Islands & $49.2^{\circ} \mathrm{N}$ & $\sim 2.1^{\circ} \mathrm{W}$ & $\begin{array}{l}57 \text { (pre-1894 stations } \\
\text { between } 9 \& 70 \mathrm{~m} \\
\text { MSL) }\end{array}$ & 1864-2007 & $\begin{array}{l}\text { Jersey Meteorological } \\
\text { Department }\end{array}$ \\
\hline Guernsey, Channel Islands & $\sim 49.5^{\circ} \mathrm{N}$ & $\sim 2.5^{\circ} \mathrm{W}$ & $34-104$ & $\begin{array}{l}\text { 1842-1881; } \\
1924-2005\end{array}$ & $\begin{array}{l}\text { Guernsey Airport Met } \\
\text { Office; Met Office } \\
\text { Hadley Centre }\end{array}$ \\
\hline Valentia, Ireland & $51.9^{\circ} \mathrm{N}$ & $10.25^{\circ} \mathrm{W}$ & $\sim 11$ & $1861-2006$ & $\begin{array}{l}\text { Schmith et al. (1997); Met } \\
\text { Office Hadley Centre }\end{array}$ \\
\hline Armagh, U.K. & $54.35^{\circ} \mathrm{N}$ & $6.65^{\circ} \mathrm{W}$ & 60 & $1833-2007$ & Armagh Observatory \\
\hline Aberdeen, U.K. & $57.2^{\circ} \mathrm{N}$ & $2.15^{\circ} \mathrm{W}$ & 27 & $1861-2005$ & $\begin{array}{c}\text { Schmith et al. (1997); Met } \\
\text { Office Hadley Centre }\end{array}$ \\
\hline Torshavn, Faroe Islands & $62.0^{\circ} \mathrm{N}$ & $6.8^{\circ} \mathrm{W}$ & $9-54$ & $1874-2007$ & Cappelen et al. (2007) \\
\hline $\begin{array}{l}\text { SW Iceland (Reykjavík } \\
\text { and Stykkishólmur) }\end{array}$ & $\begin{array}{l}\text { 64.1 } 1^{\circ} \mathrm{N} \\
\text { Reykjavík } \\
65.1^{\circ} \mathrm{N} \\
\text { Stykkishólmur }\end{array}$ & $\begin{array}{l}21.9^{\circ} \mathrm{W} \\
\text { Reykjavík } \\
22.7^{\circ} \mathrm{W} \\
\text { Stykkishólmur }\end{array}$ & $\begin{array}{l}5-61 \\
8-28\end{array}$ & $1822-2007$ & $\begin{array}{l}\text { Jónsson and Hanna } \\
\text { (2007), updated }\end{array}$ \\
\hline $\begin{array}{l}\text { Tasiilaq/Ammassalik, } \\
\text { Greenland }\end{array}$ & $65.6^{\circ} \mathrm{N}$ & $37.6^{\circ} \mathrm{W}$ & $29-53$ & 1894-2007 & Cappelen et al. (2007) \\
\hline Nordby-Esbjerg, Denmark & $55.5^{\circ} \mathrm{N}$ & $8.5^{\circ} \mathrm{E}$ & $9-54$ & 1874-2007 & Cappelen et al. (2007) \\
\hline $\begin{array}{l}\text { Vestervig-Thyboroen, } \\
\text { Denmark }\end{array}$ & $56.7^{\circ} \mathrm{N}$ & $8.3^{\circ} \mathrm{E}$ & $2-47$ & $1874-2007$ & Cappelen et al. (2007) \\
\hline Hammerodde, Denmark & $55.3^{\circ} \mathrm{N}$ & $14.8^{\circ} \mathrm{E}$ & $7-13$ & 1874-2007 & Cappelen et al. (2007) \\
\hline
\end{tabular}

data verification, only the section from 1833 onward is used in this study; it is published here for the first time. This is probably the longest-running currently available digitized subdaily pressure series from the United Kingdom, although efforts are underway to develop a longterm Exeter series (R. Allan 2007, unpublished manuscript) and improve the London series back into the eighteenth century (Cornes 2008).

The Jersey-Guernsey (Channel Islands) daily pressure series were blended for this study. Most of the Jersey readings from 1864 to the present are newly digitized and were thoroughly checked for errors for the purposes of this study by coauthor F. Le Blancq. There is only one major gap of 18 months during the early to mid-1920s. Pressure data from nearby $(\sim 40 \mathrm{~km})$ Guernsey (values from the mid-1920s onward obtained from the Hadley Centre archives, with 1843-81 data supplied by the Guernsey Airport Meteorological Office) were used as a check to verify the annual and monthly dp(abs)24 Jersey values and to extend the combined Channel Islands pressure series back to 1843 . F. Le Blancq investigated all Jersey-Guernsey (near-) simultaneous daily morning pressure differences $>3$ $\mathrm{hPa}$ for the periods of overlap (1864-81 and 19252007). In addition, the original Jersey Harbour Office (1936-40 and 1946-53) and Jersey Airport (1946-2007) readings were used as independent checks against the primary Jersey (St. Louis) readings. All flagged values were thoroughly checked and corrected or attributed to rapid pressure changes.

Geodetic data and available periods of record for the various stations are summarized in Table 1.

It is important to note some further general background information concerning barometric data procurement and quality. As part of the WASA project (Schmith et al. 1997), selected DMI (Denmark, Faroe Islands, and Greenland) series of pressure observations spanning 1874-1970 were digitized from the meteorological yearbooks, which means that the observations were station-level data corrected for index error, temperature, and, since 1893, gravity. From 1971, the DMI observations were taken from the existing digital database, all corrected. The DMI series up to 1995 were tested for homogeneity by means of a statistical test, "the standard homogeneity test" (SNHT) (Alexandersson 1986), which compares a series (the test series) with other series that are known to be homogeneous. The DMI station updates from 1996-2006 have given no problems: the stations have not moved and the instruments are the same as before 1996. All the DMI data were reduced to mean sea level. Also as part of WASA and the European and North Atlantic daily to multidecadal climate variability mean sea level pressure (MSLP) dataset (EMULATE EMSLP; Ansell et al. 2006), the Aberdeen and Valentia barometric pressure series were similarly reduced to mean sea level and 
prechecked for long-term biases and inconsistencies prior to the present study.

\section{b. Wind speed data}

Three-hourly near-surface $(10 \mathrm{~m})$ digitized wind speed data for the stations in Denmark, the Faroe Islands, and Greenland were acquired from the archives of the DMI. These are from the same sites as the air pressure measurements, except that the nearby $(\sim 24-$ $30 \mathrm{~km}$ ), better exposed Blåvandshuk Lighthouse was substituted for Nordby/Esbjerg (which is inland/ sheltered). Wind speed data were reduced to $10 \mathrm{~m}$ where measurements were substantially different from this value, most notably in the cases of anemometers located at heights of $16 \mathrm{~m} \mathrm{(36} \mathrm{m)} \mathrm{at} \mathrm{Hammerodde} \mathrm{(Thy-}$ boroen) from October 1977-August 2001 (June 1968November 2000). Early (1953-70) wind speed data from Blåvandshuk were probably derived from manual estimates using the Beaufort scale via a pennant or windsock on a 10-m flagpole (and the effect of the wind on the surrounding vegetation and/or sea surface) and converted into $\mathrm{m} \mathrm{s}^{-1}$. Wind speed data series from the five DMI stations may have inhomogeneities due to change of instruments, for which metadata are not readily available, and turbulence from the lighthouse could have affected much of the Blåvandshuk Lighthouse data.

Monthly average Jersey (Guernsey) wind speeds for 1958-2006 (1951-2005) were obtained from the Jersey Meteorological Department and Guernsey Airport Meteorological Office. Until December 1969, the effective height of the Jersey Airport anemometer was $15 \mathrm{~m}$, so we therefore applied a correction of $-10 \%$ to the recorded values to reduce them to the standard effective height of $10 \mathrm{~m}$ (HMSO 1982, p. 83). From 1970 the Jersey wind speed recordings are all within the envelope for a $10-\mathrm{m}$ effective height without the need for correction. The Guernsey Airport wind speed data are from four successive anemometers, all within $\sim 10$ 13-m effective height above ground. Both stations have generally good exposures.

\section{Methodology}

Dp(abs)24 monthly, seasonal, and annual average values were derived from daily [(0600-0900 local time (LT)] barometric pressure data for the above stations for the periods of records listed in Table 1 . These data were selected as being early morning local time to avoid any possible bias of the results due to (semi)diurnal pressure tides and to be consistent with the southwest Iceland $\mathrm{dp}(\mathrm{abs}) 24$ analysis of Jónsson and Hanna
(2007). A combined Channel Islands dp(abs)24 series (1843-2007) was spliced together from existing digitized, quality-checked Jersey and Guernsey data, using regression fitting and gap filling, along similar lines to methods used in the recent determination of a North Icelandic sea surface temperature series (Hanna et al. 2006). Due to the relatively provisional nature of the Armagh pressure series (Armagh was not one of the WASA stations), the Armagh daily dp(abs)24 values were cross checked against those of Valentia (SW Ireland) and the much-nearer ( $\sim 45-\mathrm{km}$ distant) Aldergrove (Belfast Airport), which flagged up $\sim 90$ inconsistencies (e.g., misreadings or transcription errors), which were corrected.

The $\mathrm{dp}(\mathrm{abs}) 24$ annual and seasonal averages for each station were filtered using a 21-point Gaussian filter with frequency response 0.5 at a wavelength $10 \mathrm{yr}$ and a standard deviation of 1.66667 (Burroughs 2003; Jones et al. 1999; http://www.ltrr.arizona.edu/ dmeko/notes_ 8.pdf), and they were analyzed using linear least squares regression and variance analysis for evidence of any trends. Correlation analysis was used for evidence of statistical association with other climatic parameters, namely, the $\mathrm{dp}(\mathrm{abs}) 24$ of other stations and the NAOI. We make reference to annual values of Hurrell's (1995) Azores-based index and autumn-winter values of Jones et al.'s (1997) (updated by Osborn 2006) Gibraltarbased index for the latter; $Z$ scores were used to determine outliers of annual and seasonal dp(abs) 24 of each station series for further examination.

\section{Results}

\section{a. dp(abs)24-v wind speed (Danish, Faroe Islands, Greenland, and U.K. stations)}

Correlation coefficients between annual and extended winter [December-March (DJFM)] mean $\mathrm{dp}(\mathrm{abs}) 24$ and wind speed $v$ are generally significant, although greater for winter than for annual values (Table 2): this reflects stronger prevailing winds and clearer forcing of surface pressure-winds by transient storms during winter. Figure 2 shows the close nature of the relationship between winter $\mathrm{dp}(\mathrm{abs}) 24$ and surface wind for Vestervig-Thyboroen in Denmark and Torshavn in the Faroe Islands ( $r=0.63$ in each case). Jersey $\mathrm{dp}(\mathrm{abs}) 24$ wind speed shows monthly correlations ranging from $r=0.28$ in June to 0.53 in November, and Guernsey dp(abs) 24 wind speed shows monthly correlations ranging from $r=0.15$ in April to 0.58 in December; the relationship is quite obviously least strong at both stations from April to June (not shown in table). The overall (annual and winter) relationship is strongest for Torshavn, which we attribute to its exposed 
TABLE 2. Correlation coefficients ( $r$ values) between annual and extended winter (DJFM) mean dp(abs)24 and mean wind speed at British Channel Islands and DMI stations, with $r$ values in italics (bold) significant at $p \leq 0.05$ ( $p \leq 0.01)$.

\begin{tabular}{llcc}
\hline \multicolumn{1}{c}{ Station } & \multicolumn{1}{c}{ Period } & Annual & $\begin{array}{c}\text { Winter } \\
(\text { DJFM })\end{array}$ \\
\hline Jersey & $1958-2006$ & $\mathbf{0 . 4 1}$ & $\mathbf{0 . 4 8}$ \\
Guernsey & $1951-2005$ & $\mathbf{0 . 4 3}$ & $\mathbf{0 . 5 2}$ \\
Torshavn & $1953-2006$ & $\mathbf{0 . 5 2}$ & $\mathbf{0 . 6 3}$ \\
Tasiilaq & $1958-2006$ & 0.28 & $\mathbf{0 . 4 9}$ \\
Nordby-Esbjerg/ & $1953-70 ; 1982-2006$ & 0.44 & $\mathbf{0 . 5 8}$ \\
$\quad$ Blåvandshuk & & & \\
Vestervig-Thyboroen & $1961-2005$ & 0.29 & $\mathbf{0 . 6 3}$ \\
Hammerodde & $1978-2006$ & 0.40 & 0.43 \\
\hline
\end{tabular}

oceanic location with likely minimal ageostrophic frictional effects.

\section{b. Primary features of $d p(a b s) 24$ time series from visual analysis}

Figures 3-9 show mean seasonal cycle and interannual (annual and extended winter, DJFM) dp(abs)24 for selected stations.

\section{1) Aberdeen (United Kingdom)}

Mean seasonal dp(abs)24 ranges from $\sim 4.75 \mathrm{hPa}$ in mid to late July to $>8.5 \mathrm{hPa}$ in mid-January (Fig. 3a). Notable secondary peaks around the beginning of both March and April are superimposed on the main seasonal cycle (Fig. 3a). There is a considerable standard deviation, up to $\sim 7 \mathrm{hPa}$ in midwinter, of the annual $\mathrm{dp}(\mathrm{abs}) 24$ values used to calculate each daily mean for the entire period of record (1861-2005). The running mean of annual average $\mathrm{dp}(\mathrm{abs}) 24$ exhibits distinct peaks around the 1860s, 1900s, early 1920s, 1940s, 1960s, and 1980s, and distinct troughs or minima during the late 1930s, late 1950s, and early 1970s (Fig. 3b). Figure 3c illustrates distinct seasonal disparities: for example, $\mathrm{dp}(\mathrm{abs}) 24$ was simultaneously low in winter and high in autumn around the latter half of the 1920s, but low in autumn and high in winter during the mid-1990s (also see for the wider British Isles in AL08).

\section{2) VAlentia (REPUblic of IREland)}

The dp(abs)24 time series for Valentia in SW Ireland (Fig. 4) covers a very similar time span (1861-2006) to that of Aberdeen (above). The mean seasonal cycle ranges from $<4.5 \mathrm{hPa}$ in early July to $\sim 7.5 \mathrm{hPa}$ in midwinter, which suggests on average a slightly less stormy winter climate than at Aberdeen (not shown). Again as with the Aberdeen series, secondary peaks are evident for the beginning of March and beginning of April, and there is a similar range from $\sim 3.5 \mathrm{hPa}$ in summer to $6-7$ $\mathrm{hPa}$ in winter of the standard deviation of annual values used to calculate each mean daily value. The interannual $d p(a b s) 24$ series has its three most pronounced peaks in the 1920s, very early 1960s, and early 1990s, which are far less clear (i.e., they are very much secondary peaks only) in the Aberdeen record; its two main troughs in the late 1930s and early 1970s are also seen in the Aberdeen record (see section 4b1; Fig. 3b). The first and the last main storm peaks at Valentia (i.e., the early 1920s and 1990s) appear of almost equal magnitude (also see for the wider British Isles in AL08), and $\mathrm{dp}(\mathrm{abs}) 24$ annual values around 1870 (during the closing stages of the Little Ice Age) are similar to those during much of the twentieth century. The same graph suggests that the 1940s were overall the least stormy decade of the last $>145 \mathrm{yr}$ at Valentia (Fig. 4a). This period of reduced storminess is more evident in the winter than the autumn dp(abs)24 records (Fig. 4b). Close scrutiny of the Valentia seasonal dp(abs)24 series reveals relatively high (low) winter and low (high) autumn dp(abs)24 in the 1970s to early 1990s (late 1920s) stormy or active period, in rough agreement with the Aberdeen series. As in AL08 for the British Isles, the autumn storminess peaks in the 1920s and 1990s are of similar magnitude.

\section{3) Armagh (Northern Ireland)}

Armagh, Northern Ireland (Fig. 5), has the longest $\mathrm{dp}(\mathrm{abs}) 24$ series considered in this study, stretching back continuously to 1833 . Earlier data from 1795 to 1832 are available but need substantial archival work in their verification with other relatively nearby early pressure series such as Liverpool, United Kingdom. The highest peak in dp(abs)24 is in the mid-1920s (this prominent peak is also seen in the Valentia series and for the wider British Isles in AL08; Fig. 5). Secondary peaks are evident for the 1830s, mid-1860s, early to mid-1960s, and early to mid-1980s. The low point of the Armagh dp(abs)24 series is in the early 1970s, with an almost as low point in the late 1930s. The Armagh series suggests overall slightly enhanced annual dp(abs) 24 values for the nineteenth century compared with the twentieth century (Fig. 5). Also evident is the excellent agreement between the Armagh and Valentia $\mathrm{dp}(\mathrm{abs}) 24$ annual series, from these stations $\sim 400 \mathrm{~km}$ apart, for the substantial period of overlap (1861-2006): this bolsters confidence in the underlying barometric data and indicates that the figure is presenting "real" long-term climatologies of pressure and storminess variations. 
(a)

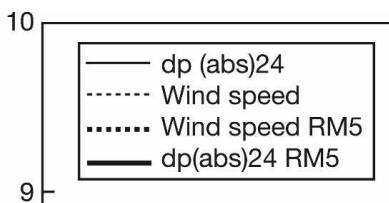

0
$\frac{0}{5}$
$\frac{0}{0}$
$\frac{0}{0}$
$\frac{0}{0}$
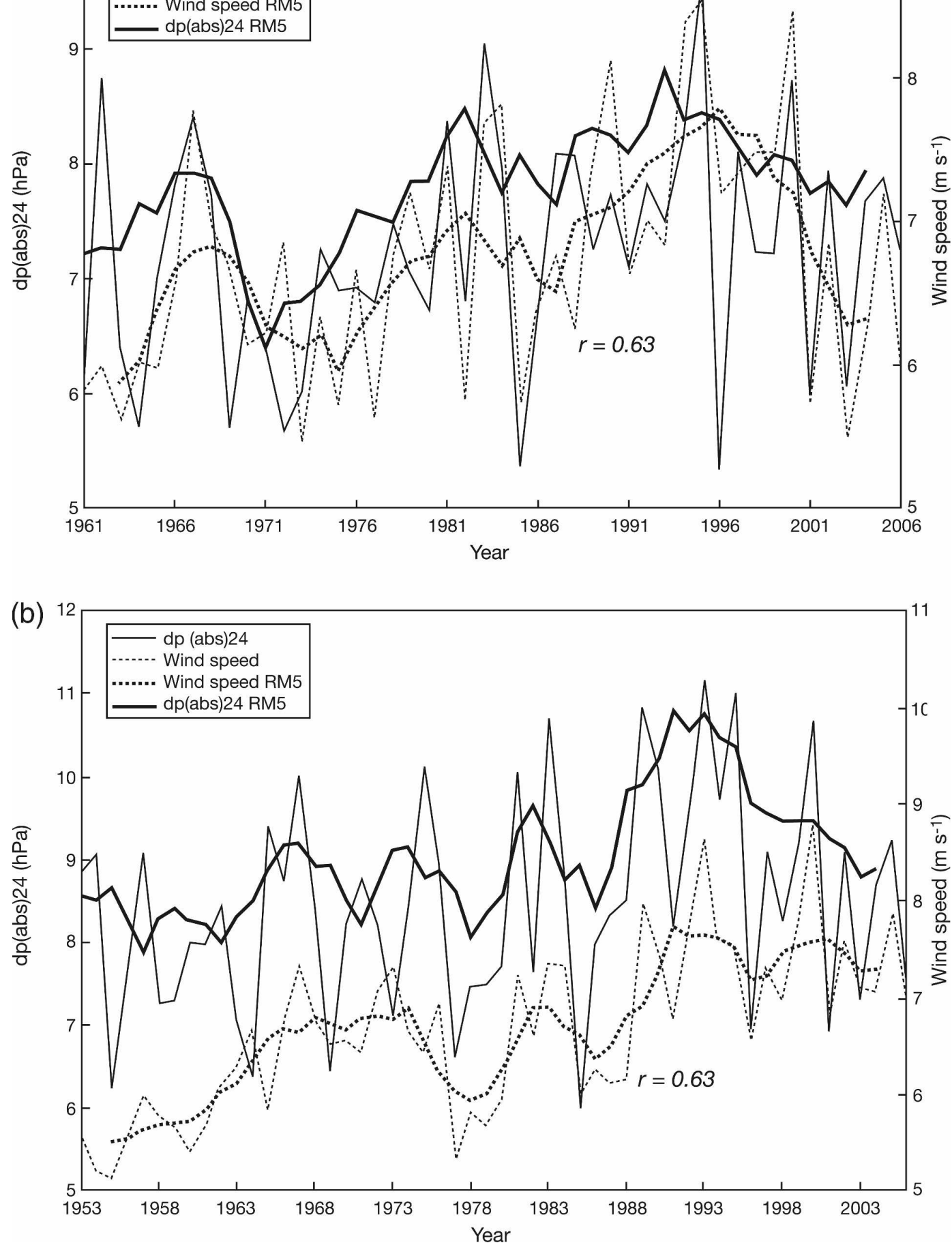

FIG. 2. (a) Comparison of Vestervig-Thyboroen (Denmark) extended winter (DJFM) dp(abs) 24 and wind speed with 5-yr running means, 1961-2006; (b) comparison of Torshavn (Faroes) extended winter (DJFM) dp(abs)24 and wind speed with 5-yr running means, 1953-2006. 
(a)

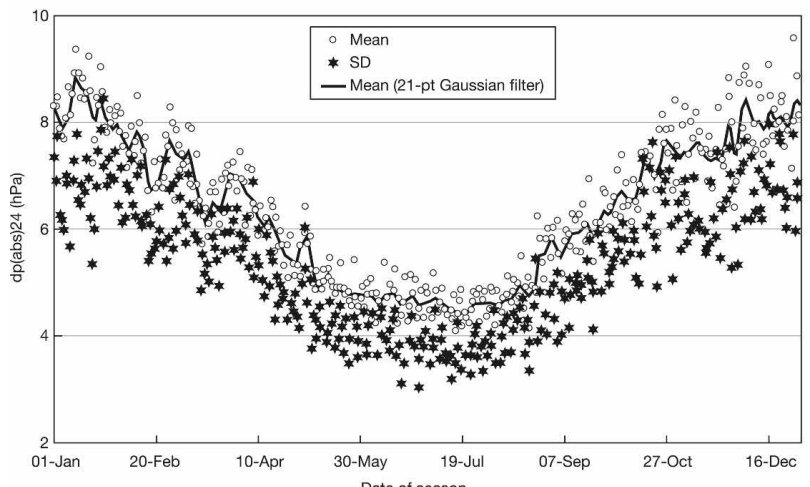

(b)

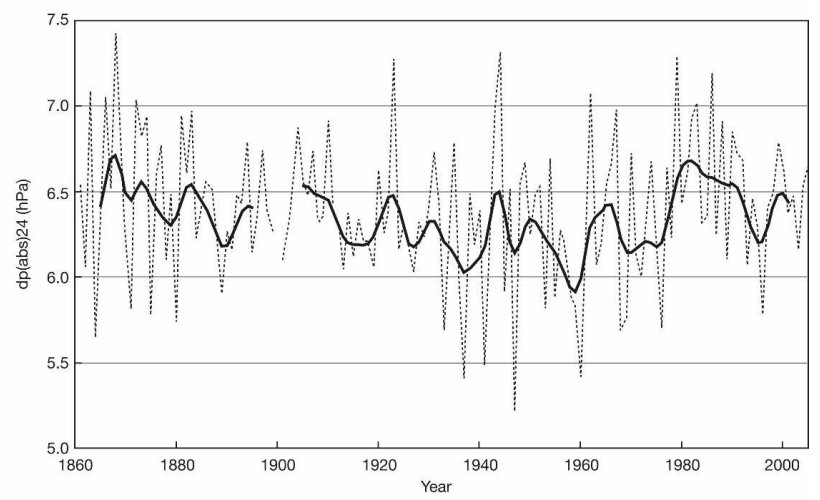

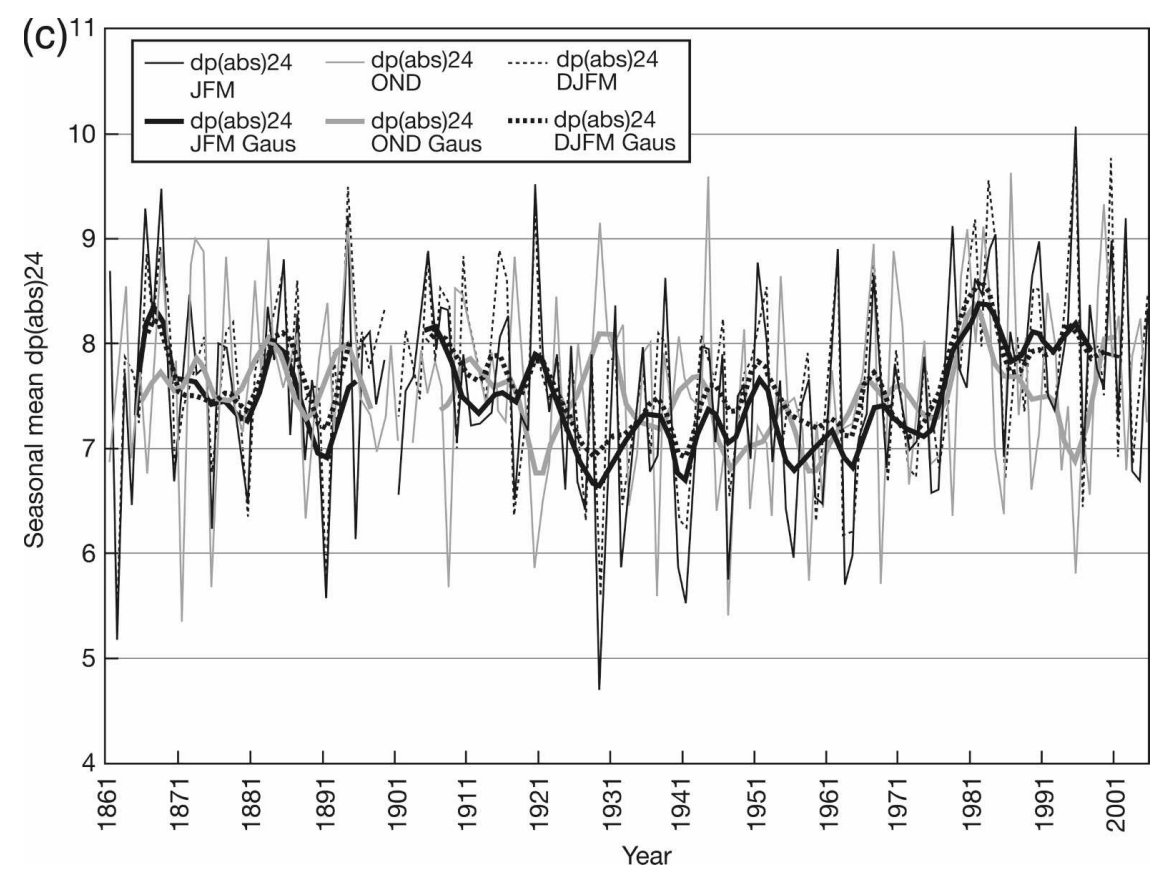

FIG. 3. (a) Annual cycle, calculated over 1861-2005, of mean and std dev of $\mathrm{dp}(\mathrm{abs}) 24$ for Aberdeen (U.K.). Symbols are plotted for each calendar day 1 January-31 December. The solid line is a 21-point Gaussian filter of mean dp(abs)24; (b) Aberdeen (U.K.) annual dp(abs) 24 with 21point Gaussian filter, 1861-2005; (c) autumn, winter, and extended winter (DJFM) seasonal mean dp(abs)24 at Aberdeen, all with 21-point Gaussian filter, 1861-2005.

\section{4) Channel Islands}

The mean seasonal dp(abs)24 cycle ranges from $\sim 3.7$ $\mathrm{hPa}$ in midsummer to $\sim 6.7 \mathrm{hPa}$ in midwinter, reflecting substantially less stormy average conditions than in the northern British Isles and western fringes of Ireland (not shown). The early March and early April mean seasonal peaks are still evident but are now matched by similar, or slightly greater, strength peaks in early November and early December (not shown). The spliced Channel Islands dp(abs)24 annual series has its main peaks around the 1860s-'70s (also an active period at Aberdeen, Armagh, and Valentia), the late 1920s (in common with Armagh and Valentia and the wider British Isles in AL08), mid to late 1960s, and around 1980: these latter two peaks are the strongest (Fig. 6a). There are some slight differences in the timing of the later two peaks from peaks in the Aberdeen, Armagh, and Val- entia series. However, the 1980 peak shows up particularly strongly in the Jersey winter series in Fig. 6b. In contrast, autumn dp(abs)24 values around 1980 are unexceptional. The 1890s and 1930s-'40s and again briefly around 1990 seem to have been relatively quiet periods in the Channel Islands.

\section{5) TORSHAVN (FAROE IsLANDS)}

The mean seasonal dp(abs) 24 cycle ranges from $\sim 4.5$ $\mathrm{hPa}$ in July to nearly $10 \mathrm{hPa}$ in midwinter at Torshavn in the wind-swept Faroe Islands (not shown). The early 1990s have relatively high annual dp(abs) 24 but not much greater than the early 1900s and late 1940s (Fig. $7 \mathrm{a}, \mathrm{b})$. The late 1950s seem to have been the "quietest" years of the entire record at Torshavn (Fig. 7a); however, split by season, the quietest winters appear to have occurred around 1940 (Fig. 7b). The early 1900s 

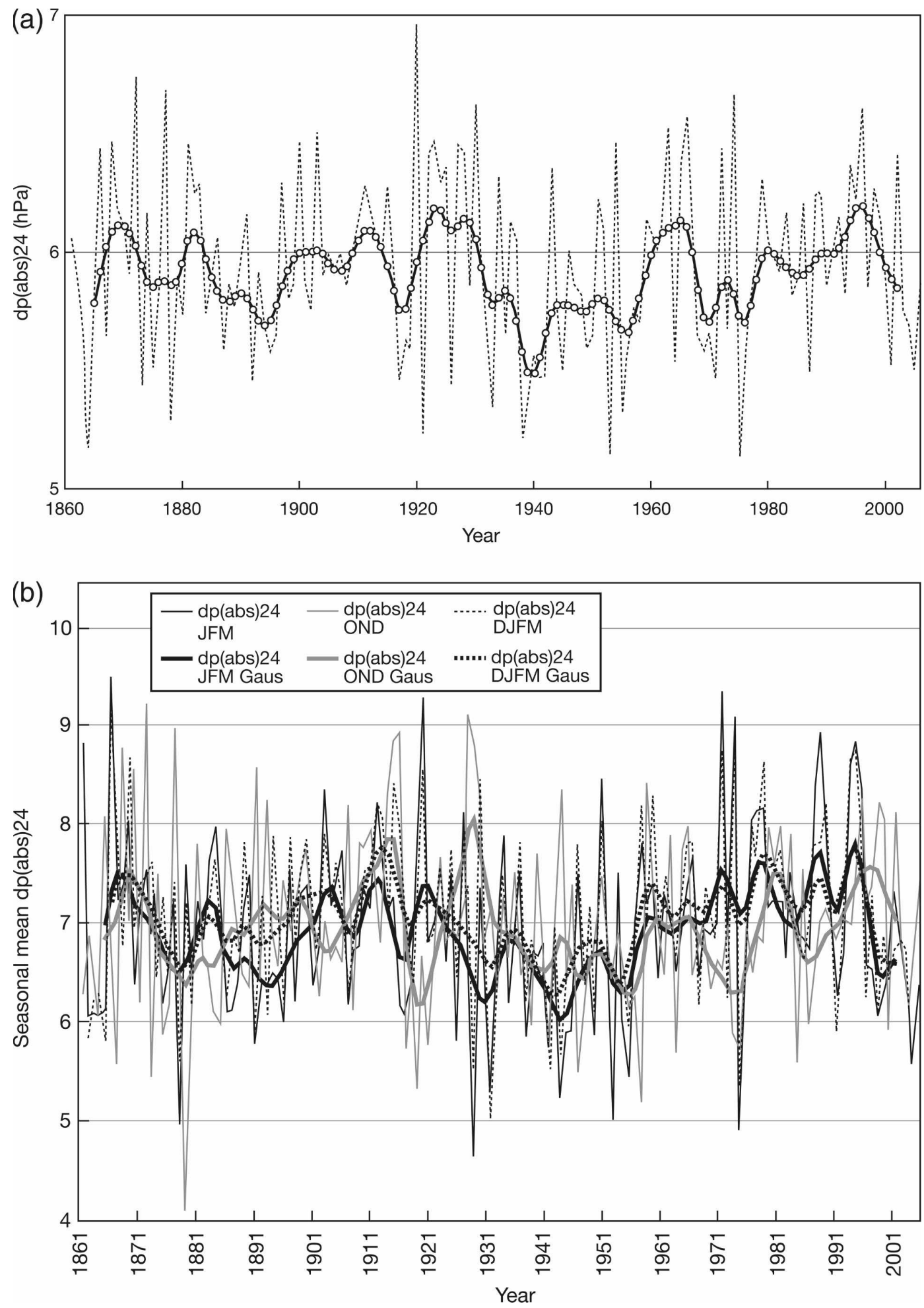

FIG. 4. (a) Valentia (Ireland) annual dp(abs)24 with 21-point Gaussian filter, 1861-2006; (b) autumn, winter, and extended winter (DJFM) seasonal mean dp(abs)24 at Valentia (Ireland), all with 21-point Gaussian filter, 18612006. 


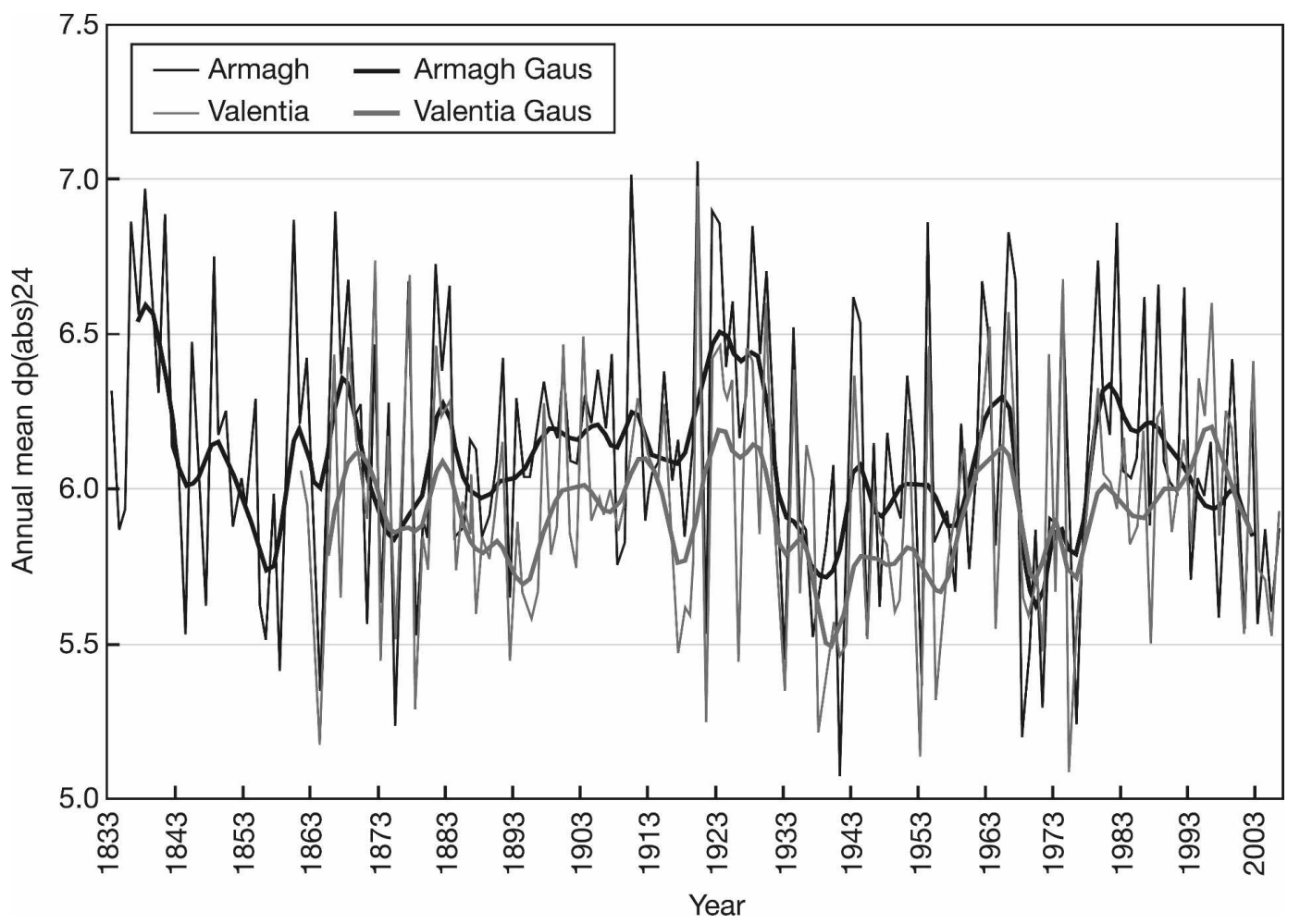

FIG. 5. Comparison of annual dp(abs)24, with 21-point Gaussian filtered versions, at Armagh and Valentia, 1833-2006.

and early 1990s peaks, and most of the interannual fluctuations in general at this station, are much more enhanced in winter than in autumn (Fig. 7c).

\section{6) Tasillaq (Greenland)}

The interannual $d p(a b s) 24$ record at Tasiilaq is more broken than at the other stations, no doubt due to the relatively remote station location (Fig. 1), but shows the principal features. There is a clear peak around 1990 and a probable peak at the start of the record around 1900, in keeping with the Torshavn series, and troughs in the late 1920s and 1960s (Fig. 8a). These peaks and troughs are in accord with similar features in the previously published SW Iceland dp(abs) 24 series (Jónsson and Hanna 2007). The 1920s trough appears to have been mainly an autumn feature, while the 1900s and 1990s peaks were primarily winter features (Fig. 8b).

\section{7) Danish Stations}

Annual dp(abs)24 series for Hammerodde Fyr (Table 1; Fig. 1) are presented in Fig. 9, along with some corresponding series for other Danish stations. Gaussian-filtered profiles reveal excellent agreement in interannual fluctuations of all three dp(abs) 24 annual series (Fig. 9a). There are two almost equal main peaks in these series in the early 1900s and around 1990. As with many of the other series, the 1950s-'60s were marked by relatively low $\mathrm{dp}(\mathrm{abs}) 24$, concentrated in autumn (Fig. 9b).

\section{c. $d p(a b s) 24$ variance and trend analysis}

Annual and extended winter (DJFM) dp(abs)24 means, standard deviations, and least squares linear regression trend-line changes for all stations are summarized in Table 3 and form very useful quantitative supplements to the above description of $\mathrm{dp}(\mathrm{abs}) 24$ changes. Only SW Iceland has a significant overall (upward) trend (but note the longer period of this series compared with most other series except Armagh), although this is only significant for its annual dp(abs)24 series and not the extended winter (DJFM) series. Regarding shorter climatological normal (standard 30-yr average) periods, significant upward trends are present in both the Armagh and Aberdeen extended winter (DJFM) series and the Tasiilaq and Hammerodde annual series for 1961-90, and also most of the Torshavn and Danish series for 1971-2000: this marks the transition between the relatively quiescent mid-twentieth century (having generally calmed down considerably 
(a)

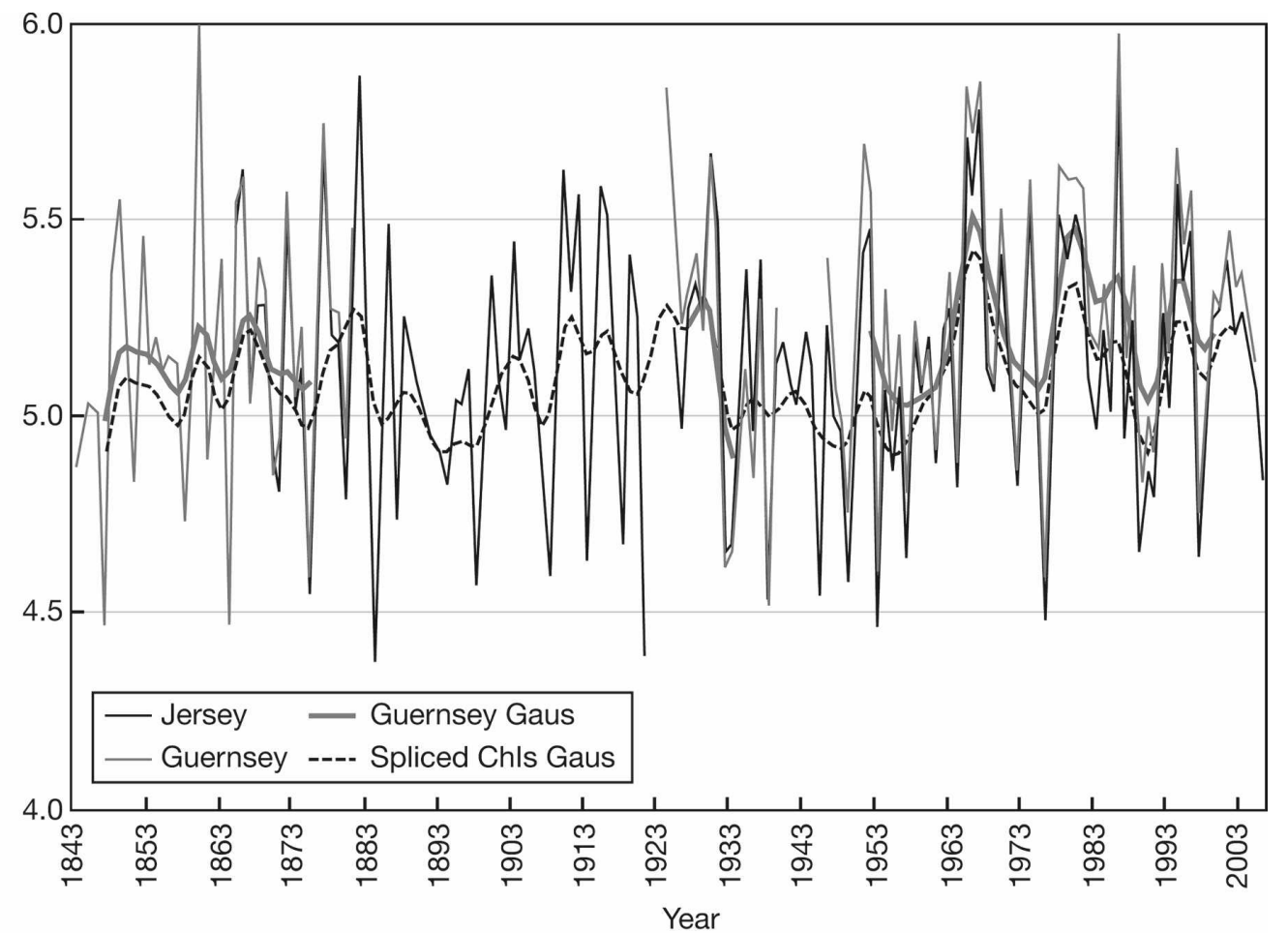

(b)
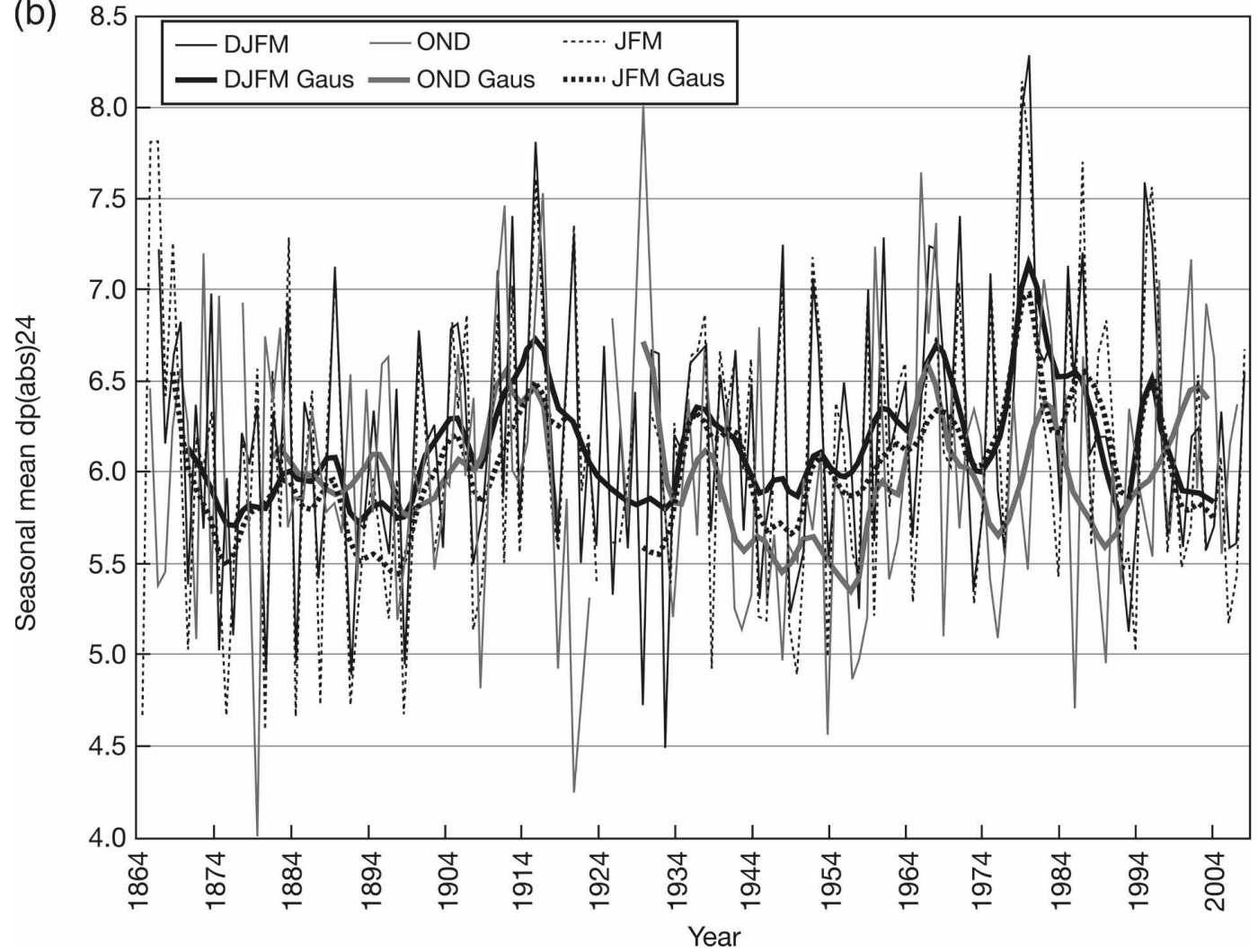

FIG. 6. (a) Annual mean dp(abs)24 at Jersey and Guernsey. The dashed curve is the 21-point, Gaussiansmoothed spliced Channel Islands annual dp(abs)24 series. The thick solid curve is the 21-point, Gaussiansmoothed Guernsey annual dp(abs)24 series. All are from 1843-2006; (b) autumn, winter, and extended winter (DJFM) seasonal mean dp(abs)24 at Jersey (U.K.), all with 21-point Gaussian filter, 1864-2007. 

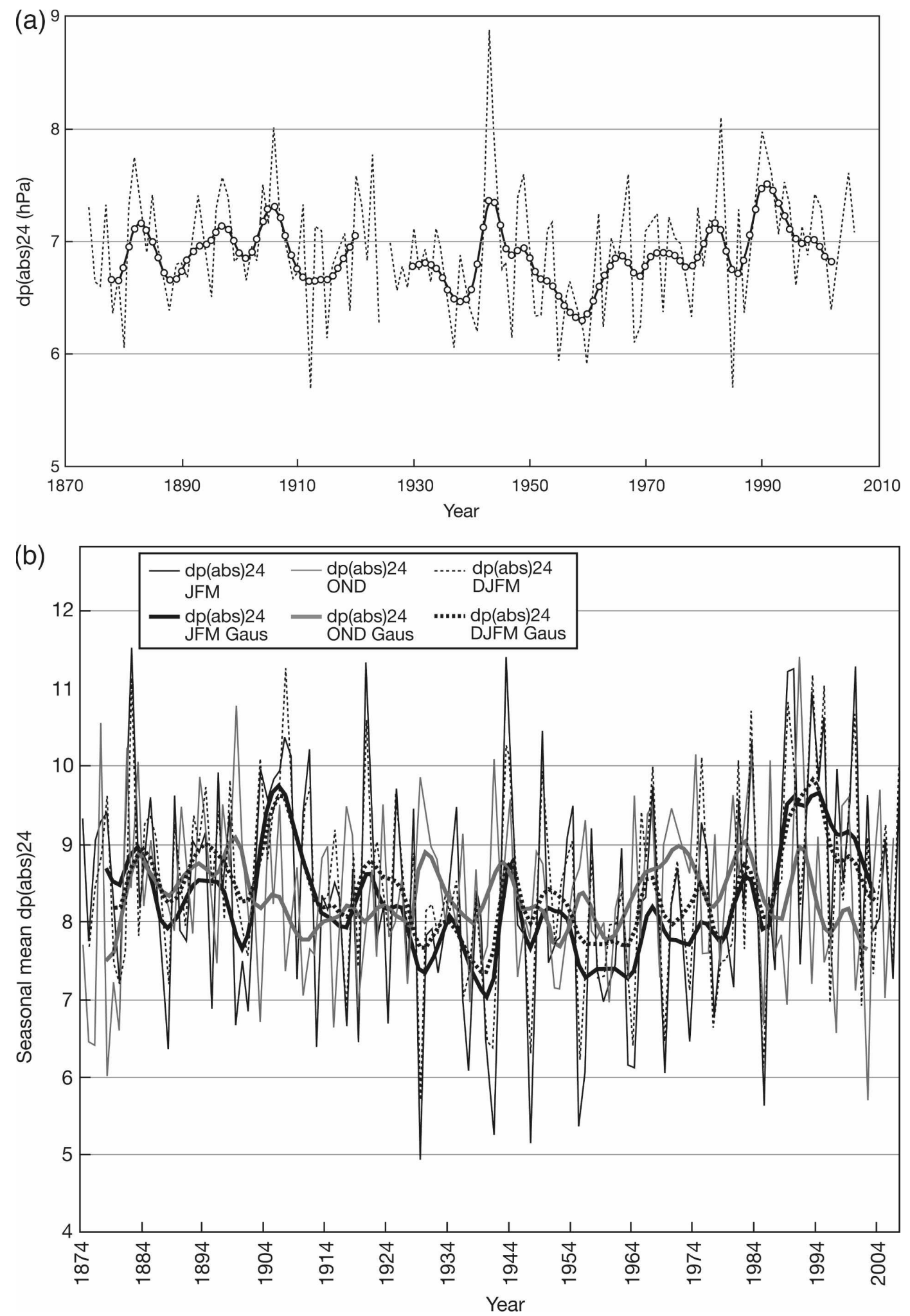

FIG. 7. (a) Torshavn (Faroe Islands) annual dp(abs)24 with 21-point Gaussian filter, 1874-2006; (b) autumn, winter, and extended winter (DJFM) seasonal mean dp(abs)24 at Torshavn (Faroe Islands), all with 21-point Gaussian filter, 1874-2007. 

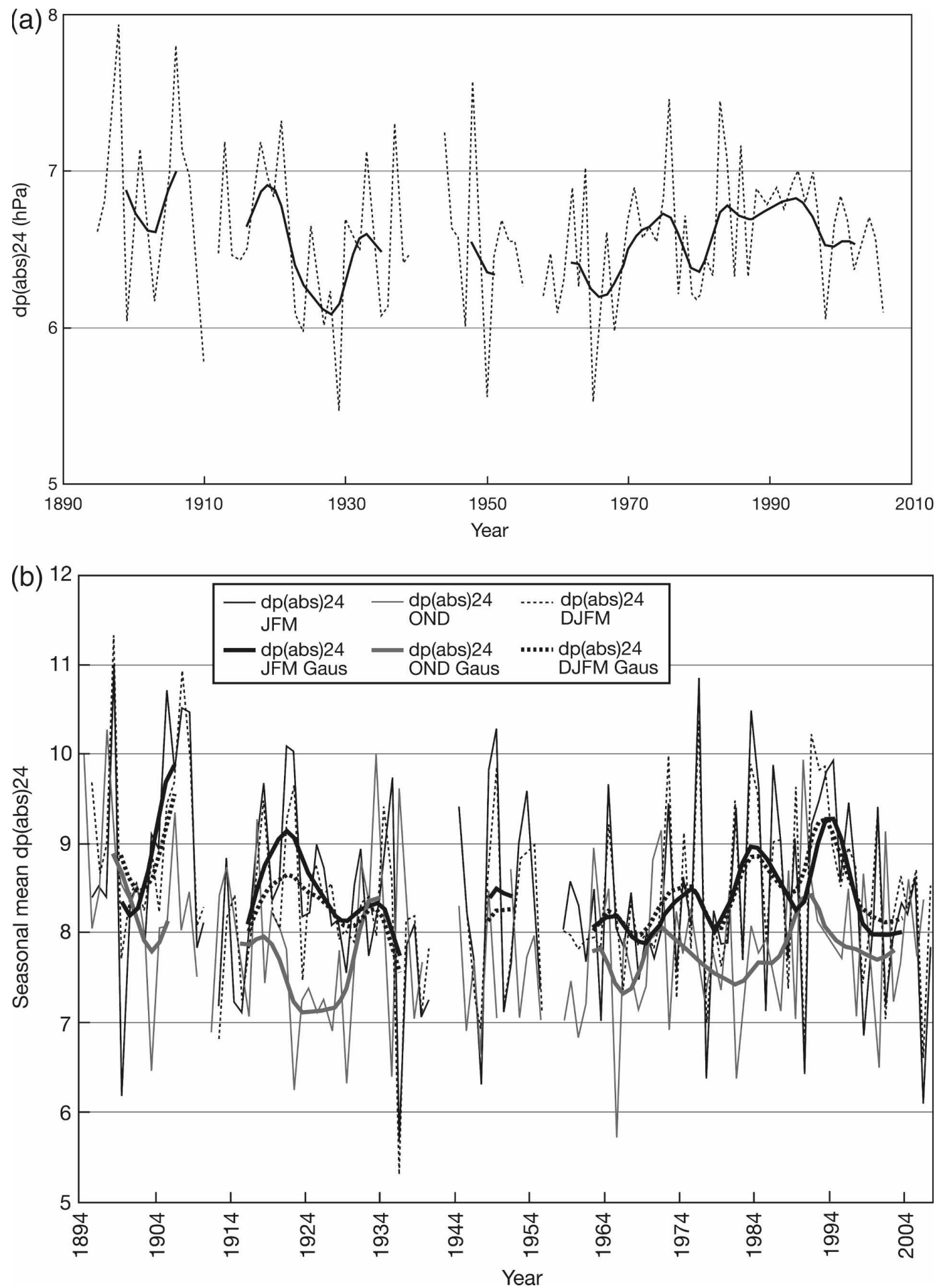

FIG. 8. (a) Tasiilaq (Greenland) annual dp(abs)24 with 21-point Gaussian filter, 1895-2006. There is a lack of data in the period September 1910-August 1911 and again from June 1940-January 1944-the latter because of the Second World War; (b) autumn, winter, and extended winter (DJFM) seasonal mean dp(abs)24 at Tasiilaq (Greenland), all with 21-point Gaussian filter, 1895-2007. 

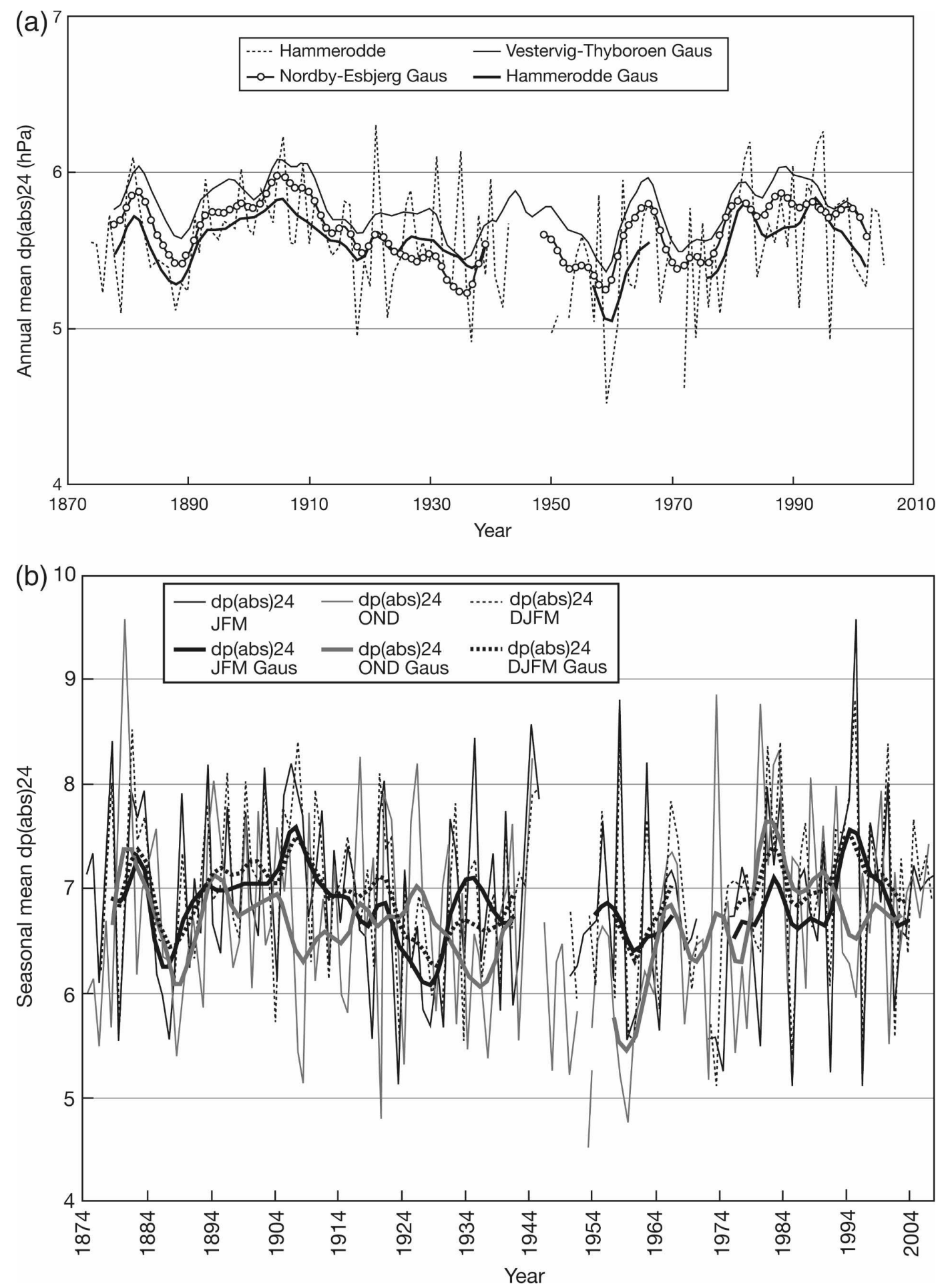

FIG. 9. (a) Hammerodde Fyr (Denmark) annual dp(abs)24 with 21-point Gaussian filter, also showing similarly filtered annual dp(abs)24 values for two other Danish stations (see Fig. 1; Table 1), 1874-2006. (b) Autumn, winter, and extended winter (DJFM) seasonal mean dp(abs)24 at Hammerodde Fyr (Denmark), all with 21-point Gaussian filter, 1874-2006. 
TABLE 3. Annual (ANN) and extended winter (DJFM) means, std devs/coefficients of variation (SD/CoV) and linear least squares regression trends of $\mathrm{dp}(\mathrm{abs}) 24$ at barometric pressure stations, with significant $(>1 \sigma)$ trends in bold type.

\begin{tabular}{|c|c|c|c|c|c|}
\hline Station/series & Season & Period & Mean & $\mathrm{SD}(\mathrm{CoV})$ & Trend/\% of mean over whole period \\
\hline \multirow[t]{7}{*}{ Channel Islands (spliced Jersey/Guernsey) } & ANN & 1843-2006 & 5.11 & $0.33(6.5)$ & $0.10 / 2.0$ \\
\hline & ANN & $1843-70$ & 5.07 & $0.37(7.4)$ & $0.28 / 5.5$ \\
\hline & ANN & $1871-1900$ & 5.12 & $0.33(6.4)$ & $-0.16 / 3.1$ \\
\hline & ANN & 1901-30 & 5.20 & $0.34(6.5)$ & $0.23 / 4.4$ \\
\hline & ANN & $1931-60$ & 5.02 & $0.29(5.8)$ & $-0.04 / 0.7$ \\
\hline & ANN & $1961-90$ & 5.19 & $0.33(6.4)$ & $-0.16 / 3.2$ \\
\hline & ANN & $1971-2000$ & 5.15 & $0.31(6.1)$ & $0.04 / 0.7$ \\
\hline \multirow[t]{6}{*}{ Jersey } & DJFM & 1866-2007 & 6.18 & $0.70(11.3)$ & $0.25 / 4.0$ \\
\hline & DJFM & 1871-1900 & 5.92 & $0.67(11.3)$ & $-0.07 / 1.1$ \\
\hline & DJFM & 1901-30 & 6.25 & $0.70(11.2)$ & $-0.37 / 5.9$ \\
\hline & DJFM & $1931-60$ & 6.12 & 0.68 (11.1) & $0.13 / 2.1$ \\
\hline & DJFM & $1961-90$ & 6.47 & $0.70(10.8)$ & $0.15 / 2.3$ \\
\hline & DJFM & 1971-2000 & 6.33 & $0.77(12.2)$ & $-0.28 / 4.4$ \\
\hline \multirow[t]{12}{*}{ Valentia } & ANN & 1861-2006 & 5.94 & $0.37(6.3)$ & $0.00 / 0.0$ \\
\hline & ANN & 1871-1900 & 5.93 & $0.36(6.1)$ & $-0.11 / 1.8$ \\
\hline & ANN & $1901-30$ & 6.06 & $0.39(6.4)$ & $0.26 / 4.3$ \\
\hline & ANN & $1931-60$ & 5.78 & $0.35(6.1)$ & $0.12 / 2.1$ \\
\hline & ANN & $1961-90$ & 5.97 & $0.38(6.3)$ & $-0.08 / 1.3$ \\
\hline & ANN & 1971-2000 & 6.01 & $0.35(5.8)$ & $0.34 / 5.6$ \\
\hline & DJFM & 1862-2006 & 7.07 & $0.81(11.5)$ & $0.11 / 1.5$ \\
\hline & DJFM & 1871-1900 & 7.00 & $0.63(9.0)$ & $0.19 / 2.7$ \\
\hline & DJFM & 1901-30 & 7.26 & $0.73(10.1)$ & $-0.16 / 2.2$ \\
\hline & DJFM & $1931-60$ & 6.75 & 0.81 (11.9) & $0.58 / 8.6$ \\
\hline & DJFM & $1961-90$ & 7.35 & $0.78(10.7)$ & $0.52 / 7.1$ \\
\hline & DJFM & 1971-2000 & 7.36 & $0.92(12.5)$ & $-0.23 / 3.1$ \\
\hline \multirow[t]{14}{*}{ Armagh } & ANN & 1833-2006 & 6.12 & $0.41(6.8)$ & $-0.18 / 2.9$ \\
\hline & ANN & $1841-70$ & 6.13 & $0.42(6.9)$ & $0.11 / 1.9$ \\
\hline & ANN & 1871-1900 & 6.08 & $0.36(5.9)$ & $0.31 / 5.1$ \\
\hline & ANN & $1901-30$ & 6.30 & $0.38(6.0)$ & $0.43 / 6.8$ \\
\hline & ANN & $1931-60$ & 5.95 & $0.39(6.5)$ & $0.13 / 2.2$ \\
\hline & ANN & 1961-90 & 6.12 & $0.47(7.7)$ & $0.12 / 2.0$ \\
\hline & ANN & 1971-2000 & 6.09 & $0.40(6.5)$ & $0.20 / 3.2$ \\
\hline & DJFM & $1833-2007$ & 7.35 & $0.76(10.3)$ & $-0.02 / 0.2$ \\
\hline & DJFM & $1841-70$ & 7.33 & $0.89(12.1)$ & $0.72 / 9.9$ \\
\hline & DJFM & 1871-1900 & 7.22 & $0.51(7.1)$ & 0.87/12.0 \\
\hline & DJFM & 1901-30 & 7.63 & $0.77(10.1)$ & $-0.07 / 1.0$ \\
\hline & DJFM & $1931-60$ & 7.09 & $0.68(9.5)$ & $0.49 / 6.8$ \\
\hline & DJFM & 1961-90 & 7.48 & $0.78(10.4)$ & $0.83 / 11.1$ \\
\hline & DJFM & 1971-2000 & 7.51 & $0.85(11.3)$ & $0.32 / 4.3$ \\
\hline \multirow[t]{12}{*}{ Aberdeen } & ANN & 1861-99 & 6.46 & $0.42(6.5)$ & $-0.17 / 2.6$ \\
\hline & ANN & 1901-2005 & 6.37 & $0.41(6.4)$ & $0.13 / 2.1$ \\
\hline & ANN & $1901-30$ & 6.38 & $0.28(4.4)$ & $-0.18 / 2.8$ \\
\hline & ANN & $1931-60$ & 6.22 & $0.50(8.0)$ & $-0.28 / 4.6$ \\
\hline & ANN & $1961-90$ & 6.47 & $0.44(6.8)$ & $0.32 / 5.0$ \\
\hline & ANN & 1971-2000 & 6.48 & $0.39(6.1)$ & $0.18 / 2.7$ \\
\hline & DJFM & 1862-99 & 13.83 & $0.81(5.9)$ & $0.40 / 2.9$ \\
\hline & DJFM & 1901-2005 & 13.73 & $0.84(6.1)$ & $0.40 / 2.9$ \\
\hline & DJFM & $1901-30$ & 13.64 & $0.83(6.1)$ & $-0.88 / 6.4$ \\
\hline & DJFM & $1931-60$ & 13.55 & $0.62(4.6)$ & $0.10 / 0.7$ \\
\hline & DJFM & 1961-90 & 13.91 & $0.89(6.4)$ & $1.05 / 7.5$ \\
\hline & DJFM & 1971-2000 & 13.88 & $0.92(6.6)$ & $0.84 / 6.0$ \\
\hline \multirow[t]{8}{*}{ Torshavn } & ANN & 1874-1924 & 6.95 & $0.46(6.7)$ & $0.06 / 0.8$ \\
\hline & ANN & 1926-2006 & 6.90 & $0.54(7.8)$ & $0.42 / 6.1$ \\
\hline & ANN & $1931-60$ & 6.75 & $0.61(9.1)$ & $-0.40 / 5.9$ \\
\hline & ANN & 1961-90 & 6.94 & $0.53(7.7)$ & $0.39 / 5.6$ \\
\hline & ANN & 1971-2000 & 7.09 & $0.50(7.0)$ & $0.38 / 5.4$ \\
\hline & DJFM & 1875-2007 & 8.47 & $1.18(13.9)$ & $0.00 / 0.1$ \\
\hline & DJFM & $1875-1900$ & 8.63 & $0.97(11.3)$ & $0.42 / 4.9$ \\
\hline & DJFM & 1901-30 & 8.59 & 1.19 (13.8) & $-1.10 / 12.8$ \\
\hline
\end{tabular}


TABLE 3. (Continued)

\begin{tabular}{|c|c|c|c|c|c|}
\hline Station/series & Season & Period & Mean & $\mathrm{SD}(\mathrm{CoV})$ & Trend/\% of mean over whole period \\
\hline \multirow[t]{3}{*}{ Torshavn } & DJFM & $1931-60$ & 8.04 & $1.04(12.9)$ & $0.04 / 0.5$ \\
\hline & DJFM & $1961-90$ & 8.37 & $1.28(15.3)$ & $1.01 / 12.1$ \\
\hline & DJFM & $1971-2000$ & 8.79 & $1.38(15.7)$ & $1.62 / 18.5$ \\
\hline \multirow[t]{14}{*}{ SW Iceland } & ANN & 1823-2006 & 7.17 & $0.70(9.7)$ & $0.77 / 10.8$ \\
\hline & ANN & $1841-70$ & 6.88 & $0.69(10.1)$ & $-0.18 / 2.7$ \\
\hline & ANN & $1871-1900$ & 7.23 & $0.62(8.6)$ & $0.95 / 13.2$ \\
\hline & ANN & $1901-30$ & 7.38 & $0.61(8.3)$ & $-0.68 / 9.2$ \\
\hline & ANN & $1931-60$ & 7.20 & $0.57(7.8)$ & $-0.08 / 1.1$ \\
\hline & ANN & $1961-90$ & 7.40 & $0.51(6.9)$ & $0.47 / 6.4$ \\
\hline & ANN & $1971-2000$ & 7.52 & $0.48(6.4)$ & $-0.02 / 0.3$ \\
\hline & DJFM & 1824-2007 & 9.06 & $1.25(13.8)$ & $0.52 / 5.7$ \\
\hline & DJFM & $1841-70$ & 8.96 & $1.34(15.0)$ & $-0.50 / 5.5$ \\
\hline & DJFM & $1871-1900$ & 9.42 & $1.04(11.1)$ & 1.07/11.4 \\
\hline & DJFM & $1901-30$ & 9.37 & $1.24(13.2)$ & $-0.79 / 8.5$ \\
\hline & DJFM & $1931-60$ & 8.77 & $1.28(14.6)$ & $0.02 / 0.2$ \\
\hline & DJFM & $1961-90$ & 9.09 & $1.07(11.7)$ & $0.80 / 8.8$ \\
\hline & DJFM & $1971-2000$ & 9.50 & $1.15(12.1)$ & $0.97 / 10.2$ \\
\hline \multirow[t]{4}{*}{ Tasiilaq/Ammassalik } & ANN & $1961-90$ & 6.58 & $0.43(6.6)$ & $0.43 / 6.6$ \\
\hline & ANN & $1971-2000$ & 6.70 & $0.36(5.3)$ & $0.07 / 1.1$ \\
\hline & DJFM & $1961-90$ & 8.36 & $0.97(11.6)$ & $0.37 / 4.4$ \\
\hline & DJFM & $1971-2000$ & 8.66 & $1.05(12.1)$ & $0.33 / 3.8$ \\
\hline \multirow[t]{7}{*}{ Nordby-Esbjerg } & ANN & 1874-2006 & 5.67 & $0.36(6.4)$ & $-0.04 / 0.8$ \\
\hline & ANN & 1874-1900 & 5.73 & $0.28(4.9)$ & $0.05 / 0.9$ \\
\hline & ANN & $1901-30$ & 5.70 & $0.32(5.6)$ & $-0.56 / 9.8$ \\
\hline & ANN & $1931-60$ & 5.48 & $0.39(7.2)$ & $-0.16 / 2.9$ \\
\hline & ANN & $1961-90$ & 5.72 & $0.45(7.8)$ & $0.24 / 4.2$ \\
\hline & ANN & $1971-2000$ & 5.73 & $0.41(7.1)$ & $0.47 / 8.2$ \\
\hline & DJFM & $1875-2007$ & 6.99 & $0.75(10.7)$ & $0.07 / 0.9$ \\
\hline \multirow[t]{5}{*}{ Nordby-Esbjerg } & DJFM & $1875-1900$ & 7.05 & $0.59(8.4)$ & $0.33 / 4.7$ \\
\hline & DJFM & 1901-30 & 7.01 & $0.73(10.5)$ & $-1.35 / 19.2$ \\
\hline & DJFM & $1931-60$ & 6.77 & $0.59(8.8)$ & $-0.05 / 0.7$ \\
\hline & DJFM & $1961-90$ & 6.98 & $0.91(13.0)$ & $0.70 / 10.1$ \\
\hline & DJFM & $1971-2000$ & 7.15 & $0.93(13.0)$ & $1.25 / 17.5$ \\
\hline \multirow[t]{12}{*}{ Vestervig-Thyboroen } & ANN & 1874-2006 & 5.81 & $0.39(6.7)$ & $-0.09 / 1.5$ \\
\hline & ANN & 1874-1900 & 5.88 & $0.29(4.9)$ & $0.11 / 1.8$ \\
\hline & ANN & 1901-30 & 5.85 & $0.31(5.3)$ & $-0.33 / 5.6$ \\
\hline & ANN & $1931-60$ & 5.66 & $0.45(8.0)$ & $-0.23 / 4.0$ \\
\hline & ANN & 1961-90 & 5.85 & $0.49(8.4)$ & $0.21 / 3.6$ \\
\hline & ANN & $1971-2000$ & 5.84 & $0.45(7.7)$ & $0.46 / 7.9$ \\
\hline & DJFM & $1875-2007$ & 7.18 & $0.80(11.2)$ & $0.01 / 0.2$ \\
\hline & DJFM & $1875-1900$ & 7.32 & $0.62(8.4)$ & $0.40 / 5.5$ \\
\hline & DJFM & 1901-30 & 7.18 & $0.75(10.4)$ & $-0.94 / 13.1$ \\
\hline & DJFM & $1931-60$ & 6.95 & $0.63(9.1)$ & $0.07 / 1.0$ \\
\hline & DJFM & 1961-90 & 7.11 & $0.96(13.5)$ & $0.73 / 10.3$ \\
\hline & DJFM & 1971-2000 & 7.32 & $1.01(13.8)$ & $1.37 / 18.7$ \\
\hline \multirow[t]{4}{*}{ Hammerodde } & ANN & 1874-1900 & 5.58 & $0.26(4.7)$ & $0.18 / 3.2$ \\
\hline & ANN & $1901-30$ & 5.65 & $0.31(5.5)$ & $-0.32 / 5.6$ \\
\hline & ANN & 1961-90 & 5.51 & $0.39(7.1)$ & $0.42 / 7.6$ \\
\hline & ANN & 1971-2000 & 5.59 & $0.44(7.8)$ & $0.62 / 11.1$ \\
\hline
\end{tabular}

from around 1900) and the relatively stormy period around 1990. On the other hand, significant negative trends occurred in the annual dp(abs)24 series of SW Iceland and all three Danish stations, and also in the DJFM dp(abs)24 series of Aberdeen, for 1901-30. Longer-period trends for 1901-2006 and 1951-2006 are insignificant in all cases except the 1951-2006 trends for
Torshavn $(+10.2 \%$ annual and $+14.5 \%$ DJFM $)$ and Hammerodde $(+8.1 \%$ annual).

\section{d. $d p(a b s) 24$ cross-correlation analysis}

Cross-correlation coefficients ( $r$ values) between annual mean dp(abs)24 for available periods of record for the various stations, with significant values highlighted, 
TABLE 4. Cross-correlation coefficients ( $r$ values) between annual mean dp(abs) 24 of barometric pressure stations/series used in this study, with $r$ values in italics (bold) significant at $p \leq 0.05(p \leq 0.01)$. Values above right (below left) of central diagonal are for 1874-2006 (1951-2006).

\begin{tabular}{|c|c|c|c|c|c|c|c|c|c|c|}
\hline & $\begin{array}{l}\text { Channel } \\
\text { Isles }\end{array}$ & Valentia & Armagh & Aberdeen & Torshavn & $\begin{array}{r}\mathrm{SW} \\
\text { Iceland }\end{array}$ & Tasiilaq & $\begin{array}{l}\text { Nordby- } \\
\text { Esbjerg }\end{array}$ & $\begin{array}{l}\text { Vestervi- } \\
\text { Thyboroen }\end{array}$ & Hammerodde \\
\hline Channel Islands & 1.00 & 0.55 & 0.51 & 0.30 & -0.07 & -0.19 & -0.27 & 0.33 & 0.27 & 0.15 \\
\hline Valentia & 0.50 & 1.00 & 0.74 & 0.35 & 0.21 & 0.04 & -0.14 & 0.17 & 0.16 & -0.02 \\
\hline Armagh & 0.52 & 0.74 & 1.00 & 0.64 & 0.34 & 0.13 & -0.08 & 0.41 & 0.46 & 0.18 \\
\hline Aberdeen & 0.41 & 0.36 & 0.68 & 1.00 & 0.63 & 0.33 & 0.10 & 0.67 & 0.72 & 0.38 \\
\hline Torshavn & -0.01 & 0.17 & 0.22 & 0.60 & 1.00 & 0.61 & 0.47 & 0.40 & 0.46 & 0.32 \\
\hline SW Iceland & -0.04 & 0.07 & 0.08 & 0.35 & 0.67 & 1.00 & 0.67 & 0.15 & 0.18 & 0.09 \\
\hline Tasiilaq & -0.17 & -0.10 & -0.10 & 0.14 & 0.51 & 0.64 & 1.00 & 0.08 & 0.08 & 0.08 \\
\hline Nordby-Esbjerg & 0.43 & 0.17 & 0.47 & 0.72 & 0.39 & 0.13 & 0.05 & 1.00 & 0.93 & 0.76 \\
\hline Vestervig-Thyboroen & 0.36 & 0.13 & 0.46 & 0.75 & 0.45 & 0.21 & 0.09 & 0.96 & 1.00 & 0.76 \\
\hline Hammerodde & 0.23 & -0.03 & 0.20 & 0.51 & 0.43 & 0.25 & 0.13 & 0.80 & 0.82 & 1.00 \\
\hline
\end{tabular}

are summarized in Table 4. As expected, the $r$ values tend to be higher the closer stations are together: note, for example, the very high overall $r=0.93$ between the Nordby-Esbjerg and Verstervig-Thyboroen $(\sim 140 \mathrm{~km}$ apart, both Denmark; Fig. 1) dp(abs)24. The two Irish stations, Valentia, and Armagh are correlated at $r=$ 0.74 , even though they are $\sim 400 \mathrm{~km}$ apart on opposite sides of Ireland, and Tasiilaq (southeast Greenland) and SW Iceland-nearly $700 \mathrm{~km}$ apart-are correlated at $r=0.67$ (Table 4). High correlations of stations (relatively) close together give greater confidence in the individual $d p(a b s) 24$ series. The high correlations between stations $\geq 400-700 \mathrm{~km}$ apart strongly suggest that $\mathrm{dp}(\mathrm{abs}) 24$ has considerable spatial coherence. The significant negative correlations between Jersey and Tasiilaq can be ascribed to north-south displacements of the storm track and the reversal of vorticity across the jet stream (Barry and Chorley 2003, 130-131).

\section{e. $d p(a b s) 24-N A O I$ correlation analysis}

Correlation coefficients between extended winter (DJFM) dp(abs)24 for the various stations and two principal NAOIs, also for winter, are summarized in Table 5; a visual indication of the nature of the $\mathrm{dp}$ (abs)24-NAO relationship, for both the year as a whole and autumn and winter seasons, is shown in Fig. 10. The strongest $\mathrm{dp}(\mathrm{abs}) 24-\mathrm{NAOI}$ relationships, up to $r=0.79$, are found for Torshavn (Faroes) and are greater than those derived for SW Iceland. The dp(abs)24-NAOI relationships become progressively weaker on moving farther away from the main NAOI axis and subpolar jet stream. Of the stations studied here, Jersey has the weakest statistical association with the NAOIs. Although correlations between winter NAOI and winter dp(abs) 24 are statistically significant for the three Danish stations, this is only true if one takes the whole (1875-2006) series. It is not true for the most part within the 30-yr time frames in the series, except for the most recent (1971-2000). This probably indicates changes in the character of NAO (in its strength and/or positions of its nodes or centers of action) for this later compared with previous periods, as hinted by Jones et al. (2003). On the other hand, Tasiilaq 30-yr winter dp(abs)24 and NAOIs are significantly correlated only for the 1931-60 period.

\section{f. $d p(a b s) 24$ extremes-High and low years/seasons and links with $\mathrm{NAO} /$ historic weather events}

The five highest and five lowest $d p(a b s) 24$ winter (DJFM) values during the period 1875-2006 are shown for each series in Table 6. Several years stand out from the table as having either high or low anomalies in multiple series.

Winter 1994/95 (denoted as 1995 in the table) was the highest-ranked dp(abs)24 winter at Aberdeen, Armagh, and each of the three Danish stations, the third-highest dp(abs)24 winter at Valentia and the fourth-highest dp(abs)24 winter at Torshavn. Given the often significant relationship between dp(abs)24 and NAOI at these stations, it is no coincidence that winter 1994/95 has the joint second-highest value in the Hurrell (1995) NAOI (which begins in 1864), with more persistent, stronger westerly winds penetrating farther east across northwest Europe, as indicated by the MSLP chart in Fig. 11f; MSLP anomalies were $>8$ $\mathrm{hPa}$ below the December-March mean over a wide area between Iceland and Norway. Winter 1994/95 dp(abs)24 was 3.2 (3.1) standard deviations above its long-term mean at the Danish station Nordby-Esbjerg (Vestervig-Thyboroen).

Winter 1993/94 also features prominently in our table, with the second-highest $\operatorname{dp}(\mathrm{abs}) 24$ at Armagh and the fourth-highest dp(abs)24 at both Jersey and Valentia; it has the ninth- highest NAOI value accord- 
TABLE 5. Correlation coefficients ( $r$ values) between extended winter (DJFM) (annual in brackets) dp(abs)24 and NAOI (Hurrell 1995; Jones et al. 1997), with $r$ values in italics (bold) significant at $p \leq 0.05(p \leq 0.01)$. N.B., * means Hurrell index only available from 1864 .

\begin{tabular}{|c|c|c|c|}
\hline Station & Period & Hurrell & Jones et al. \\
\hline \multirow[t]{6}{*}{ Jersey } & 1866-2005 & $-0.13(-0.04)$ & -0.09 \\
\hline & 1871-1900 & -0.25 & -0.21 \\
\hline & $1901-30$ & -0.08 & 0.01 \\
\hline & $1931-60$ & -0.48 & -0.41 \\
\hline & $1961-90$ & -0.16 & -0.18 \\
\hline & $1971-2000$ & -0.18 & -0.18 \\
\hline \multirow[t]{6}{*}{ Valentia } & $1862-2005$ & $0.12(\mathbf{0 . 2 7})$ & 0.15 \\
\hline & $1871-1900$ & -0.02 & 0.03 \\
\hline & $1901-30$ & 0.43 & 0.51 \\
\hline & $1931-60$ & -0.13 & -0.01 \\
\hline & $1961-90$ & 0.04 & -0.04 \\
\hline & $1971-2000$ & -0.09 & -0.11 \\
\hline \multirow[t]{7}{*}{ Armagh } & $1833-2005^{*}$ & $0.30(0.33)$ & 0.36 \\
\hline & 1841-1870* & $\mathrm{X}$ & 0.42 \\
\hline & $1871-1900$ & 0.19 & 0.25 \\
\hline & $1901-30$ & 0.61 & 0.67 \\
\hline & $1931-60$ & 0.00 & 0.04 \\
\hline & $1961-90$ & 0.22 & 0.20 \\
\hline & $1971-2000$ & 0.16 & 0.17 \\
\hline \multirow[t]{6}{*}{ Aberdeen } & $1862-2005$ & $0.50(0.39)$ & 0.52 \\
\hline & 1871-1900 & 0.33 & 0.41 \\
\hline & $1901-30$ & 0.46 & 0.49 \\
\hline & $1931-60$ & 0.54 & 0.49 \\
\hline & $1961-90$ & 0.49 & 0.50 \\
\hline & $1971-2000$ & 0.53 & 0.57 \\
\hline \multirow[t]{6}{*}{ Torshavn } & $1875-2005$ & $0.68(0.58)$ & 0.67 \\
\hline & $1875-1900$ & 0.58 & 0.63 \\
\hline & $1901-30$ & 0.65 & 0.61 \\
\hline & $1931-60$ & 0.76 & 0.70 \\
\hline & $1961-90$ & 0.64 & 0.68 \\
\hline & $1971-2000$ & 0.77 & 0.79 \\
\hline \multirow[t]{6}{*}{ SW Iceland } & $1823-2005^{*}$ & $0.53(0.58)$ & 0.49 \\
\hline & 1871-1900 & 0.46 & 0.43 \\
\hline & $1901-30$ & 0.49 & 0.40 \\
\hline & $1931-60$ & 0.68 & 0.58 \\
\hline & $1961-90$ & 0.55 & 0.49 \\
\hline & $1971-2000$ & 0.56 & 0.50 \\
\hline \multirow[t]{5}{*}{ Tasiilaq } & $1895-2005$ & $0.35(0.33)$ & 0.26 \\
\hline & $1901-30$ & 0.30 & 0.19 \\
\hline & $1931-60$ & 0.68 & 0.61 \\
\hline & $1961-90$ & 0.26 & 0.19 \\
\hline & $1971-2000$ & 0.25 & 0.19 \\
\hline \multirow[t]{6}{*}{ Nordby-Esbjerg } & $1875-2005$ & $\mathbf{0 . 2 8}(0.10)$ & 0.28 \\
\hline & $1875-1900$ & 0.03 & 0.12 \\
\hline & $1901-30$ & 0.20 & 0.17 \\
\hline & $1931-60$ & 0.14 & 0.00 \\
\hline & $1961-90$ & 0.27 & 0.32 \\
\hline & $1971-2000$ & 0.51 & 0.56 \\
\hline \multirow[t]{6}{*}{ Vestervig-Thyboroen } & $1875-2005$ & $\mathbf{0 . 3 7}(0.17)$ & 0.37 \\
\hline & $1875-1900$ & 0.11 & 0.2 \\
\hline & $1901-30$ & 0.38 & 0.35 \\
\hline & $1931-60$ & 0.26 & 0.12 \\
\hline & $1961-90$ & 0.32 & 0.37 \\
\hline & $1971-2000$ & 0.56 & 0.62 \\
\hline \multirow[t]{6}{*}{ Hammerodde } & $1875-2005$ & $\mathbf{0 . 2 6}(0.05)$ & 0.26 \\
\hline & $1875-1900$ & 0.03 & 0.10 \\
\hline & $1901-30$ & 0.24 & 0.22 \\
\hline & $1931-60$ & -0.03 & -0.09 \\
\hline & $1961-90$ & 0.22 & 0.27 \\
\hline & $1971-2000$ & 0.52 & 0.58 \\
\hline
\end{tabular}



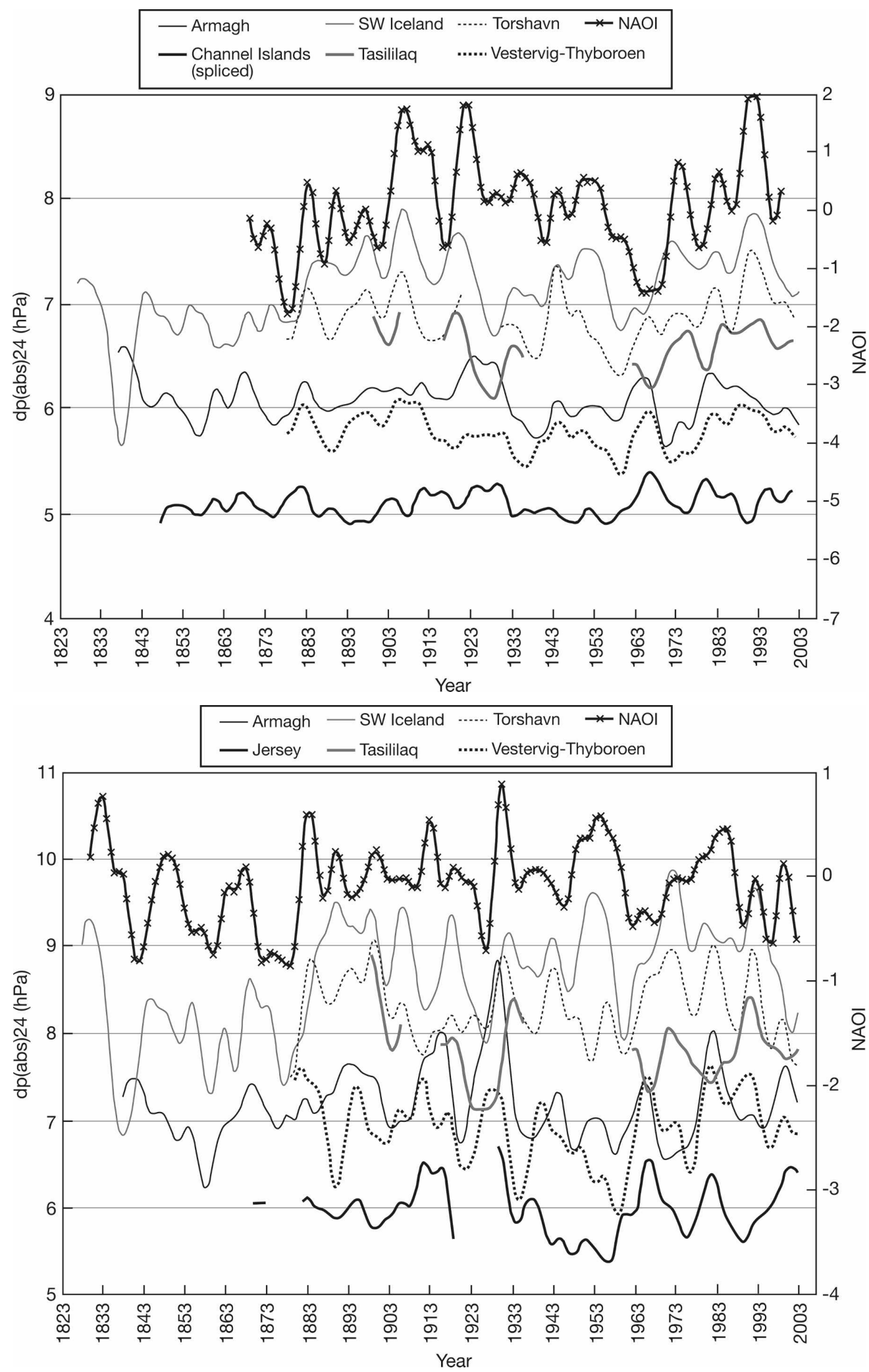

FIG. 10. (a) Annual dp(abs) 24 for sample stations in British Isles, Iceland, Greenland, Faroe Islands, and Denmark, and annual (Hurrell) NAO index, all plotted using 21-point Gaussian filter. (b) Autumn (October-December) dp(abs)24 for sample stations in British Isles, Iceland, Greenland, Faroe Islands, and Denmark, and autumn (Jones et al. 1997) NAO index, all plotted using 21-point Gaussian filter. (c) Winter (January-March) dp(abs)24 for sample stations in British Isles, Iceland, Greenland, Faroe Islands, and Denmark, and winter (Jones et al. 1997) NAO index, all plotted using 21-point Gaussian filter. 


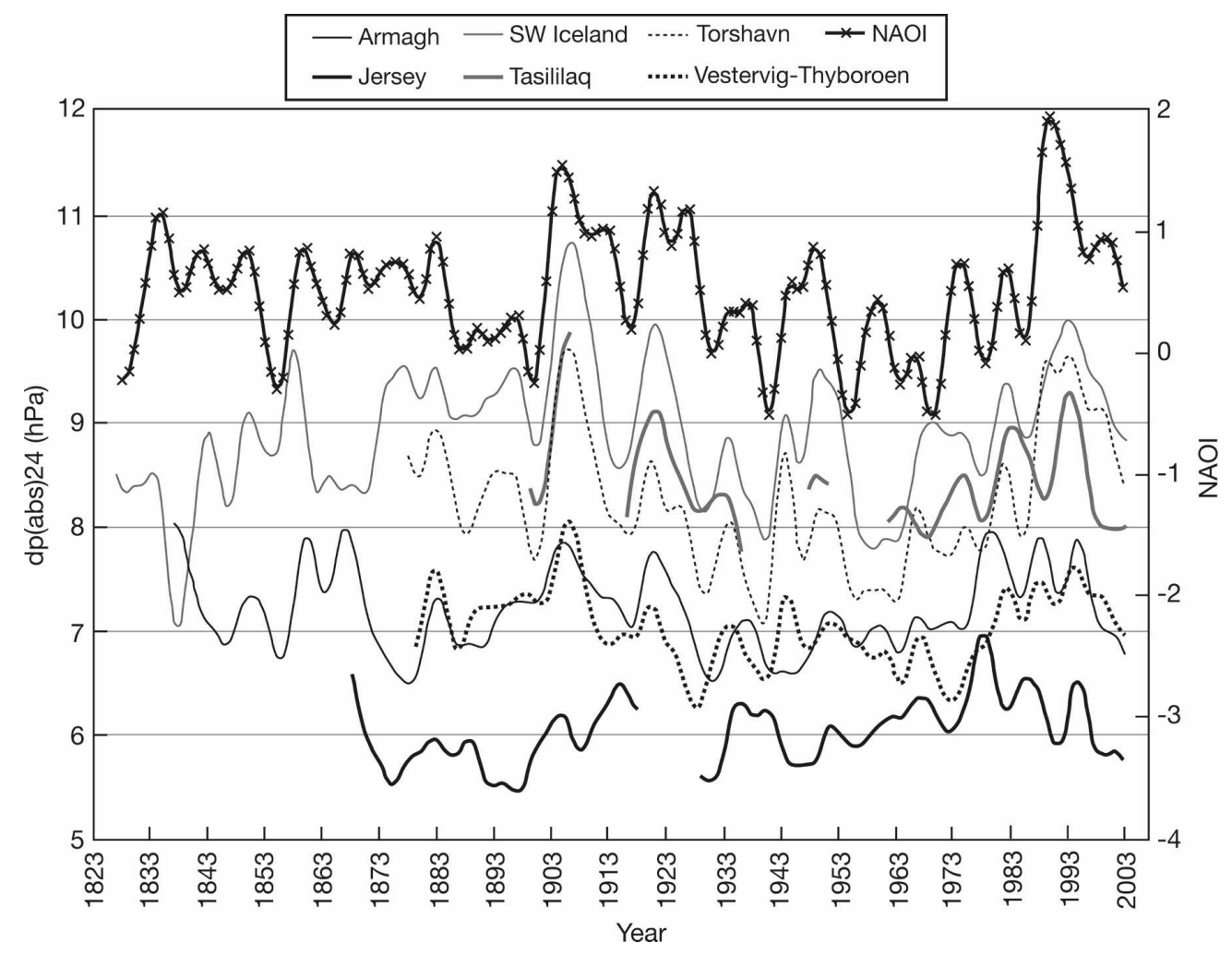

FIG. 10. (Continued)

ing to the Hurrell (1995) list, and MSLP anomalies north of the United Kingdom and Ireland $\sim 5 \mathrm{hPa}$ below the winter mean (Fig. 11e). However, neither 1994 nor 1995 appears on a list of 1891-2007 Danish storms (Cappelen and Rosenørn 2007; storms classified according to 10 -min mean wind speed $\geq 21 \mathrm{~m} \mathrm{~s}^{-1}$ estimated to cover at least $10 \%$ of the country), so the main features of the atmospheric circulation in those years over Denmark may have been an increase in the mean wind speed, as indicated by Fig. 11, rather than a direct effect on increased wind storms.

Winter 1906/07 features prominently as having had the highest winter $d p(a b s) 24$ at Torshavn, the secondhighest winter $\mathrm{dp}(\mathrm{abs}) 24$ for SW Iceland and at Tasiilaq, Nordby-Eesbjerg, and Verstervig-Thyboroen, and the third-highest dp(abs)24 at Hammerodde; it also features on Cappelen and Rosenørn's (2007) Danish storm list, with two noted westerly storms in January and February 1907. However, despite its prevailing strong westerly circulation (Fig. 11b), winter 1906/07 does not have any storms assessed as being of historic interest over the British Isles and northwest Europe in the storm catalog by Lamb (1991), and it is only ranked 20th on the Hurrell (1995) NAOI list. This may be related to MSLP anomalies southwest of Ireland being some 8 $\mathrm{hPa}$ above normal that winter (seen as an incursion of higher pressure toward SW United Kingdom in Fig. $11 \mathrm{~b}$ ), which seems to have quelled the worst ravages of the vigorous westerlies around the neighborhood of the British Isles.

Winter 1978/79 was the highest-ranked dp(abs)24 winter at Jersey, which at $8.3 \mathrm{hPa}$ was 3.0 standard deviations above the long-term (1875-2006) mean, and the fifth- (sixth) highest dp(abs)24 winter during this period at Valentia (Armagh); significantly, this winter had a low Hurrell NAOI $(-2.25)$ and a generally "stalled" zonal circulation (Fig. 11c) but with MSLP anomalies of 4-5 hPa below the December-March average over southern England, France, and the Bay of Biscay, illustrating the complexity of the relationship between $d p(a b s) 24$ and NAO. In keeping with the pattern of a negative NAOI but vigorous atmospheric circulation, extensive and prolonged snow storms occurred in southern Denmark during late December 1978 and early January 1979 (Cappelen and Rosenørn 2007). Later that same winter, on 13-14 February 1979, a long easterly wind stream of continental polar air precipitated a fierce easterly storm over the Channel and south coast of the United Kingdom, which attained a gradient wind of $\sim 100 \mathrm{kt}\left(51 \mathrm{~m} \mathrm{~s}^{-1}\right)$ and resulted in the breaching of the famous Chesil Bank and the isolation of Portland as an island (Lamb 1991). 
TABLE 6. Five highest and five lowest dp(abs)24 extended winter (DJFM) seasonal values from 1875 (Tasiilaq only from 1895 ) to 2006 inclusive, with $Z$ scores indicating anomalous departure from mean (with $Z$ scores $\geq \pm 3.0$ in bold). Years are for January.

\begin{tabular}{|c|c|c|c|c|}
\hline Station & High rank/year & $\mathrm{dp}(\mathrm{abs}) 24(\mathrm{Z})$ & Low rank/year & $\mathrm{dp}(\mathrm{abs}) 24(Z)$ \\
\hline \multirow[t]{5}{*}{ Jersey } & 1/1979 & $8.28(3.0)$ & $1 / 1932$ & $4.48(-2.4)$ \\
\hline & 2/1978 & $7.91(2.5)$ & $2 / 1880$ & $4.61(-2.2)$ \\
\hline & $3 / 1915$ & $7.82(2.4)$ & $3 / 1929$ & $4.74(-2.1)$ \\
\hline & 4/1994 & $7.57(2.0)$ & $4 / 1891$ & $4.88(-1.8)$ \\
\hline & $5 / 1970$ & $7.40(1.8)$ & $5 / 1884$ & $4.90(-1.8)$ \\
\hline \multirow[t]{5}{*}{ Valentia } & $1 / 1974$ & $8.92(2.4)$ & $1 / 1932$ & $5.00(-2.6)$ \\
\hline & $2 / 1972$ & $8.79(2.2)$ & $2 / 1975$ & $5.34(-2.2)$ \\
\hline & 3/1995 & $8.77(2.2)$ & $3 / 1953$ & $5.48(-2.0)$ \\
\hline & 4/1994 & $8.66(2.0)$ & $4 / 1929$ & $5.51(-2.0)$ \\
\hline & $5 / 1979$ & $8.63(2.0)$ & $5 / 1942$ & $5.53(-1.9)$ \\
\hline \multirow[t]{5}{*}{ Armagh } & $1 / 1995$ & $9.16(2.4)$ & $1 / 1932$ & $5.41(-2.6)$ \\
\hline & $2 / 1994$ & $8.94(2.1)$ & $2 / 2005$ & $5.97(-1.8)$ \\
\hline & $3 / 1920$ & $8.92(2.1)$ & $3 / 1929$ & $6.00(-1.8)$ \\
\hline & $4 / 1910$ & $8.84(2.0)$ & $4 / 1976$ & $6.08(-1.7)$ \\
\hline & $5 / 1916$ & $8.64(1.7)$ & $5 / 1948$ & $6.26(-1.5)$ \\
\hline \multirow[t]{5}{*}{ Aberdeen } & $1 / 1995$ & $9.79(2.6)$ & $1 / 1929$ & $5.61(-2.5)$ \\
\hline & $2 / 2000$ & $9.77(2.5)$ & $2 / 1891$ & $5.64(-2.5)$ \\
\hline & $3 / 1983$ & $9.58(2.3)$ & $3 / 1963$ & $6.19(-1.8)$ \\
\hline & $4 / 1894$ & $9.49(2.2)$ & $4 / 1964$ & $6.22(-1.8)$ \\
\hline & $5 / 1920$ & $9.36(2.0)$ & $5 / 1941$ & $6.26(-1.8)$ \\
\hline \multirow[t]{5}{*}{ Torshavn } & $1 / 1907$ & $11.25(2.4)$ & $1 / 1929$ & $5.72(-2.3)$ \\
\hline & $2 / 1882$ & $11.22(2.4)$ & $2 / 1985$ & $6.01(-2.1)$ \\
\hline & $3 / 1993$ & $11.17(2.3)$ & $3 / 1955$ & $6.23(-1.9)$ \\
\hline & $4 / 1995$ & $11.01(2.2)$ & $4 / 1947$ & $6.32(-1.8)$ \\
\hline & $5 / 1989$ & $10.84(2.0)$ & $5 / 1941$ & $6.38(-1.8)$ \\
\hline \multirow[t]{5}{*}{ SW Iceland } & $1 / 1949$ & $12.56(2.8)$ & 1/1936 & $6.81(-3.0)$ \\
\hline & $2 / 1907$ & $12.25(2.4)$ & $2 / 2001$ & $6.85(-3.0)$ \\
\hline & $3 / 1992$ & $11.60(1.8)$ & 3/1947 & $6.91(-2.9)$ \\
\hline & $4 / 1925$ & $11.30(1.5)$ & $4 / 1960$ & $6.94(-2.9)$ \\
\hline & $5 / 1898$ & $11.25(1.5)$ & $5 / 1912$ & $7.05(-2.8)$ \\
\hline \multirow{5}{*}{$\begin{array}{l}\text { Tasiilaq (N.B. years 1911, } \\
\text { 1941-43 and 1956/57 } \\
\text { missing) }\end{array}$} & 1/1898 & $11.31(3.0)$ & 1/1936 & $5.30(-3.2)$ \\
\hline & $2 / 1907$ & $10.93(2.6)$ & $2 / 2006$ & $6.61(-1.9)$ \\
\hline & $3 / 1976$ & $10.60(2.2)$ & $3 / 1990$ & $6.62(-1.9)$ \\
\hline & $4 / 1991$ & $10.22(1.8)$ & $4 / 1912$ & $6.83(-1.6)$ \\
\hline & $5 / 1908$ & $10.13(1.8)$ & $5 / 1947$ & $6.94(-1.5)$ \\
\hline \multirow[t]{5}{*}{ Nordby-Esbjerg } & $1 / 1995$ & $9.37(3.2)$ & $1 / 1985$ & $5.35(-2.2)$ \\
\hline & $2 / 1907$ & $8.71(2.3)$ & $2 / 1959$ & $5.40(-2.1)$ \\
\hline & $3 / 1962$ & $8.66(2.2)$ & $3 / 1964$ & $5.49(-2.0)$ \\
\hline & $4 / 1983$ & $8.50(2.0)$ & $4 / 1996$ & $5.50(-2.0)$ \\
\hline & $5 / 2000$ & $8.42(1.9)$ & $5 / 1929$ & $5.53(-1.9)$ \\
\hline \multirow[t]{3}{*}{ Vestervig-Thyboroen } & 1/1995 & $9.63(3.1)$ & $1 / 1996$ & $5.34(-2.3)$ \\
\hline & $2 / 1907$ & $9.09(2.4)$ & $2 / 1985$ & $5.38(-2.2)$ \\
\hline & $3 / 1983$ & $9.05(2.3)$ & $3 / 1959$ & $5.54(-2.0)$ \\
\hline \multirow[t]{2}{*}{ Vestervig-Thyboroen } & $4 / 1962$ & $8.75(2.0)$ & $4 / 1972$ & $5.68(-1.9)$ \\
\hline & $5 / 2000$ & $8.73(1.9)$ & $5 / 1969$ & $5.71(-1.8)$ \\
\hline \multirow[t]{5}{*}{ Hammerodde } & $1 / 1995$ & $8.89(2.5)$ & $1 / 1973$ & $5.11(-2.3)$ \\
\hline & $2 / 1881$ & $8.53(2.0)$ & 2/1996 & $5.23(-2.2)$ \\
\hline & $3 / 1907$ & $8.39(1.8)$ & $3 / 1985$ & $5.25(-2.1)$ \\
\hline & $4 / 1983$ & $8.38(1.8)$ & $4 / 1923$ & $5.55(-1.8)$ \\
\hline & $5 / 2000$ & $8.38(1.8)$ & $5 / 1933$ & $5.56(-1.7)$ \\
\hline
\end{tabular}

Winter 1982/83 was the third-highest dp(abs)24 winter at Aberdeen and Vestervig-Thyboroen and the fourth-highest dp(abs)24 winter at Nordby-Esbjerg and Hammerodde; it ranks sixth highest in the Hurrell (1995) 1864-2006 NAOI list, with MSLP anomalies ranging from $-3 \mathrm{hPa}$ over Iceland to $>7 \mathrm{hPa}$ west of sea area Fitzroy. A very vigorous winter circulation persisted from mid-December through mid-February (Fig. 11d). Lamb (1991) commented that winter 1982/83 was remarkable for its frequent severe storms and unusually deep cyclones-including three exceptionally deep systems of central MSLP 930-934 hPa-over the 
North Atlantic and Europe. Two events in January and February 1983, with widespread effects and gradient winds of up to $100 \mathrm{kt}\left(51 \mathrm{~m} \mathrm{~s}^{-1}\right)$, are prominently featured in Lamb's (1991) Severe Storm Index. A strong hurricane-like storm affected Denmark in January 1983 (Cappelen and Rosenørn 2007).

Finally, winter $1897 / 98$ had a mean dp(abs)24 of $11.31 \mathrm{hPa}$ at Tasiilaq (Greenland), equaling 3.0 standard deviations above the 1875-2006 mean. That year, despite its unexceptional NAOI, had a vigorous westerly circulation over the British Isles and much of northwest Europe, with tightly bound MSLP streamlines (Fig. 11a). Winter 1897/98 also features prominently in the historic storm catalogs, with noted gales and storms in November 1897 (Lamb 1991) and January and March 1898 (Cappelen and Rosenørn 2007).

The years 1929 and 1932 feature prominently in lowranking dp(abs)24 winters. Indeed, 1928/9 is the lowestranking dp(abs)24 winter (out of 1875-2006) at Aberdeen and Torshavn, the third-lowest-ranking dp(abs)24 winter at Jersey and Armagh, the fourth-lowestranking $d p(a b s) 24$ winter at Valentia, and the fifthlowest-ranking dp(abs)24 winter at Nordby-Esbjerg. This seems directly linked with a high MSLP anomaly of over $8 \mathrm{hPa}$ covering a wide area between the north cape of Scotland, the Faroes, and Norway, with prevailing high pressure anchored firmly over southern Germany (Fig. 11g). Winter 1931/32 has the lowest $\mathrm{dp}(\mathrm{abs}) 24$ at Jersey, Valentia, and Armagh. This reflects prevailing anticyclonic conditions over and south of the British Isles that winter (Fig. 11h), with extensive MSLP anomalies of $>6 \mathrm{hPa}$. There are hardly any events cataloged for these two winters in the Danish storm list (Cappelen and Rosenørn 2007). However, Lamb (1991) cataloged two notable storm events for November 1928, although he highlighted the narrow corridor of one of these, and an isolated storm during November 1931. The latter was noted as having occurred during a relatively gale-free month; clearly, certain individual storms are likely to be missed by taking mean winter dp(abs)24 (or MSLP or NAOI) statistics.

Winter 1935/36 was the lowest-ranking dp(abs)24 winter for both SW Iceland and Tasilaq, but the reason is not obvious from the MSLP chart (Fig. 11i), although a clue might be given by MSLP anomalies of 3 and 5 $\mathrm{hPa}$ over, respectively, Iceland and southeast Greenland that winter.

The winter of 1995/96 is conspicuous at the Danish stations, as it is the lowest-ranking $\operatorname{dp}($ abs $) 24$ winter at Vestervig-Thyboroen, the second-lowest-ranking $\mathrm{dp}(\mathrm{abs}) 24$ winter at Hammerodde, and the fourthlowest-ranking dp(abs)24 winter at Nordby-Esbjerg. Not surprisingly, there are no Danish storms during this winter (Cappelen and Rosenørn 2007). Of course, winter 1995/96 is well known as it represents a major sudden switch in phase of NAOI from highly positive the previous winter 1994/95 (see above) to the sixth-mostnegative NAOI value of the 1864-2006 period in 1995/ 96 (e.g., Hurrell et al. 2003) (Fig. 11j), with a blocking anticyclone over eastern Europe-which would have its greatest influence on the Danish stations.

The principal features of our Valentia (Ireland) dp(abs)24 annual and winter series (Fig. 4) are mirrored in the Valentia midwinter (January) hourly gale record based on anemometer data covering the period 1869-2005 (Hickey 2008). The hourly gale record shows similar peaks in the early 1920s, early 1960s, and mid1980s to around 1990, also with relatively high values in the 1870s and 1880s, suggesting - just like the dp(abs)24 record (see section 4b2) - relatively stormy conditions at Valentia toward the end of the Little Ice Age. On the other hand, the early 1950s stands out as a relatively quiet period in the hourly gale record, as with the $\mathrm{dp}(\mathrm{abs}) 24$ series. Similarly, the main aspects of our Armagh (Northern Ireland) dp(abs) 24 annual series (Fig. 5) are well captured in a twice-daily instrumentalobservational (anemometer) record for the station spanning 1844-1999, which similarly shows prominent peaks for around 1900, the early 1920s, late 1950s, and 1980s, and similar low points in the late 1930s and around 1970 (Hickey 2003). The 1920s and 1960s peaks in Irish storminess fit well with an annual incidence of flooding record (with excessive rainfall as the main cause of flooding) in Cork City from 1841-1988, which highlights peak flooding frequencies in 1925-40 and 1953-66 (Tyrrell and Hickey 1991). This comparison also serves to point out just one potential practical application of $\mathrm{dp}(\mathrm{abs}) 24$ in relating historical, recent (and later future) changes in atmospheric circulation to human impacts. Relatively quiet conditions at both Valentia and Armagh in the most recent decade (since the early 1990s) are confirmed by an additional analysis of hours with gales and gusts to gale force at five Irish stations from 1991 to 2005 (Hickey 2008); this analysis also confirms a general peak of gale activity in 1994-a year that features prominently in our list of highranking $d p(a b s)$ winters at both Valentia and Armagh (Table 6).

Although there appear to be good qualitative links between dp(abs)24 and previously documented northwest European-and more specifically United Kingdom, Danish, and Irish-storms, we caution that the dp(abs) 24 analysis should in essence be viewed as a long-term climate index. For example, severe storms in Jersey in September 1869, October 1887, November 1940, and October 1964 (Le Blancq 1988) all produced 


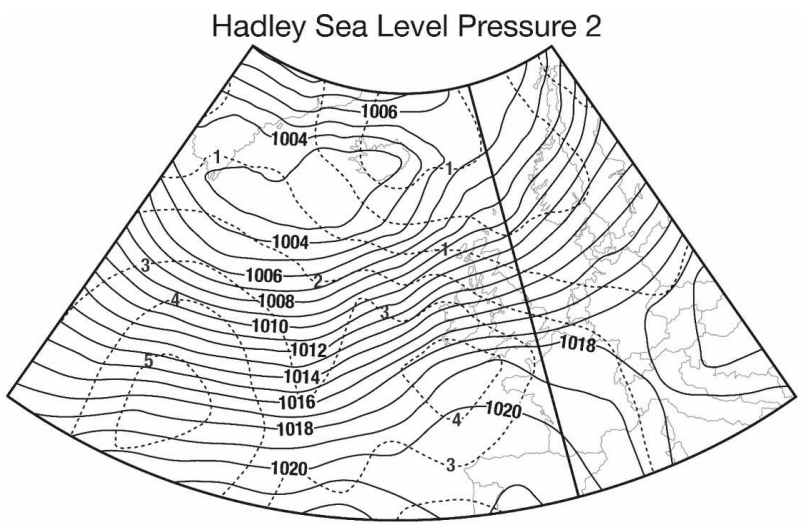

Dec 1897 to Mar 1898

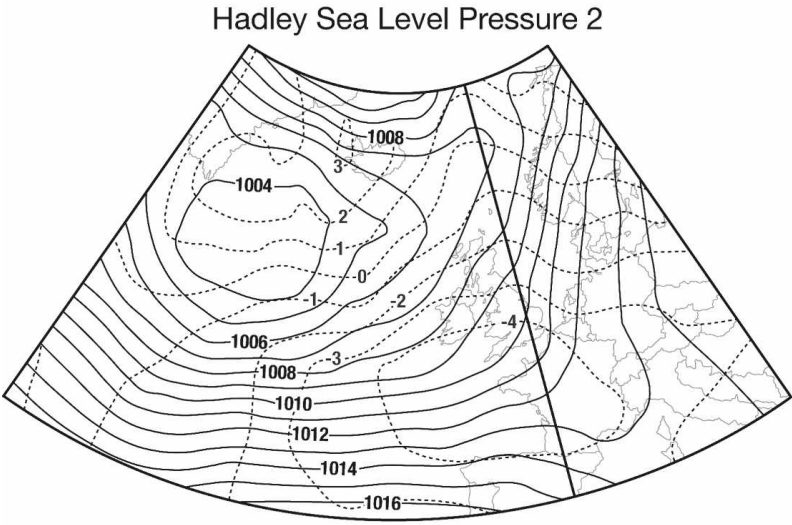

Dec 1978 to Mar 1979

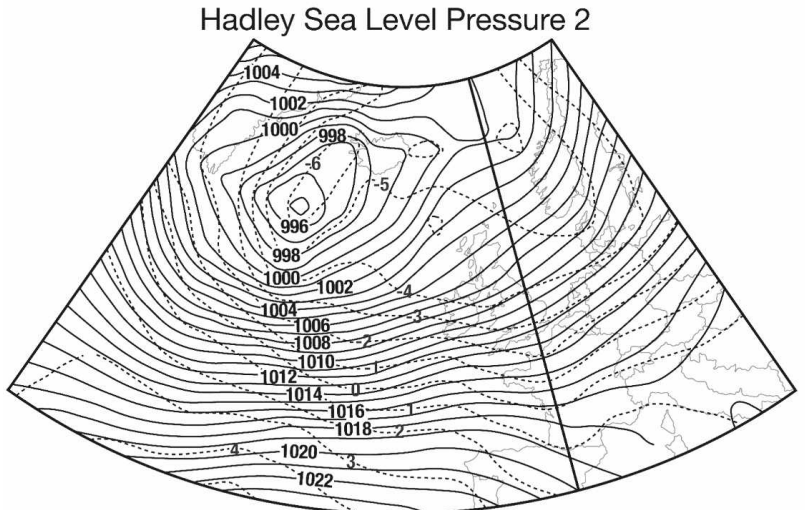

Dec 1993 to Mar 1994

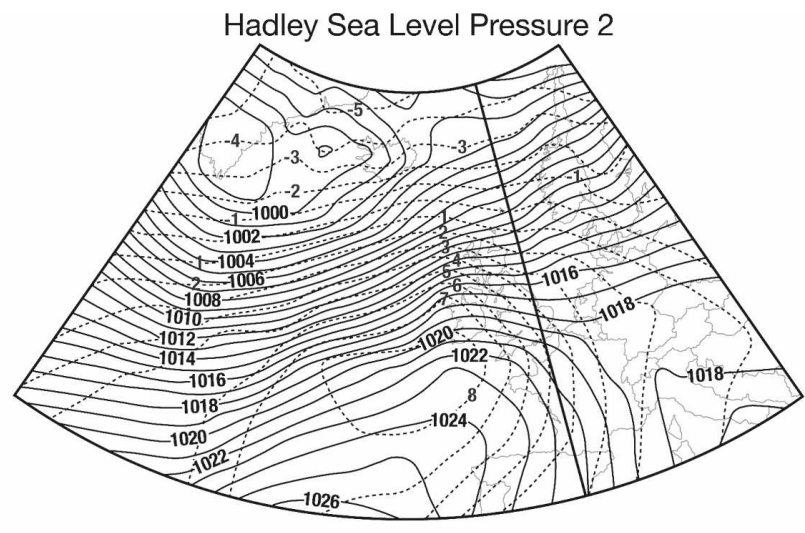

Dec 1906 to Mar 1907

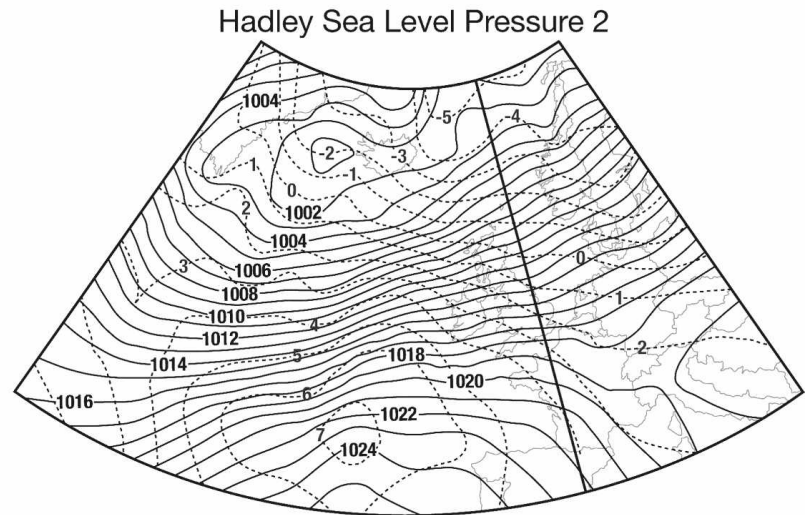

Dec 1982 to Mar 1983

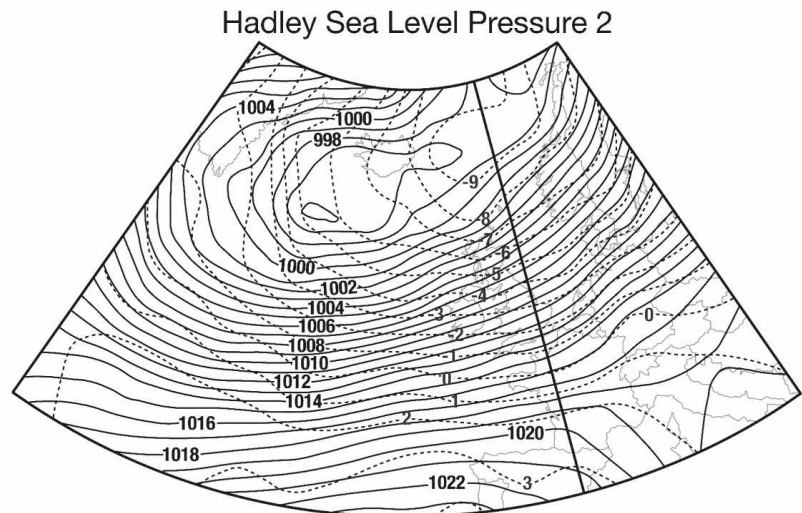

Dec 1994 to Mar 1995

FIG. 11. Extended winter (DJFM) MSLP (solid lines) and MSLP anomalies (dashed lines), all contours at 1-hPa intervals, based on Hadley Centre Sea Level Pressure Dataset 2 (HadSLP2) data and produced using the interactive plotting tool on the NOAA/ Cooperative Institute for Research in Environmental Sciences (CIRES)/Climate Diagnostics Center Web site at http:// www.cdc.noaa.gov/cgi-bin/Pressure/printpage.pl. MSLP and anomaly maps. The first six panels are for unusually high dp(abs) 24 winter seasons, and the last four panels are for unusually low $\mathrm{dp}(\mathrm{abs}) 24$ winter seasons, as discussed in the text section $4 \mathrm{f}$ and catalogued in Table 6.

severe gales or storm-force mean winds and serious damage, yet these years did not feature as unusual in the $\mathrm{dp}(\mathrm{abs}) 24$ analysis. The storms did not occur at the fixed 0900 LT survey time, so values only varied from
0.3 to $10.7 \mathrm{hPa}$. Neither was the severe storm of 26 December 1999 captured: although it caused widespread severe damage over northern France and record-breaking pressure variations (Le Blancq and 

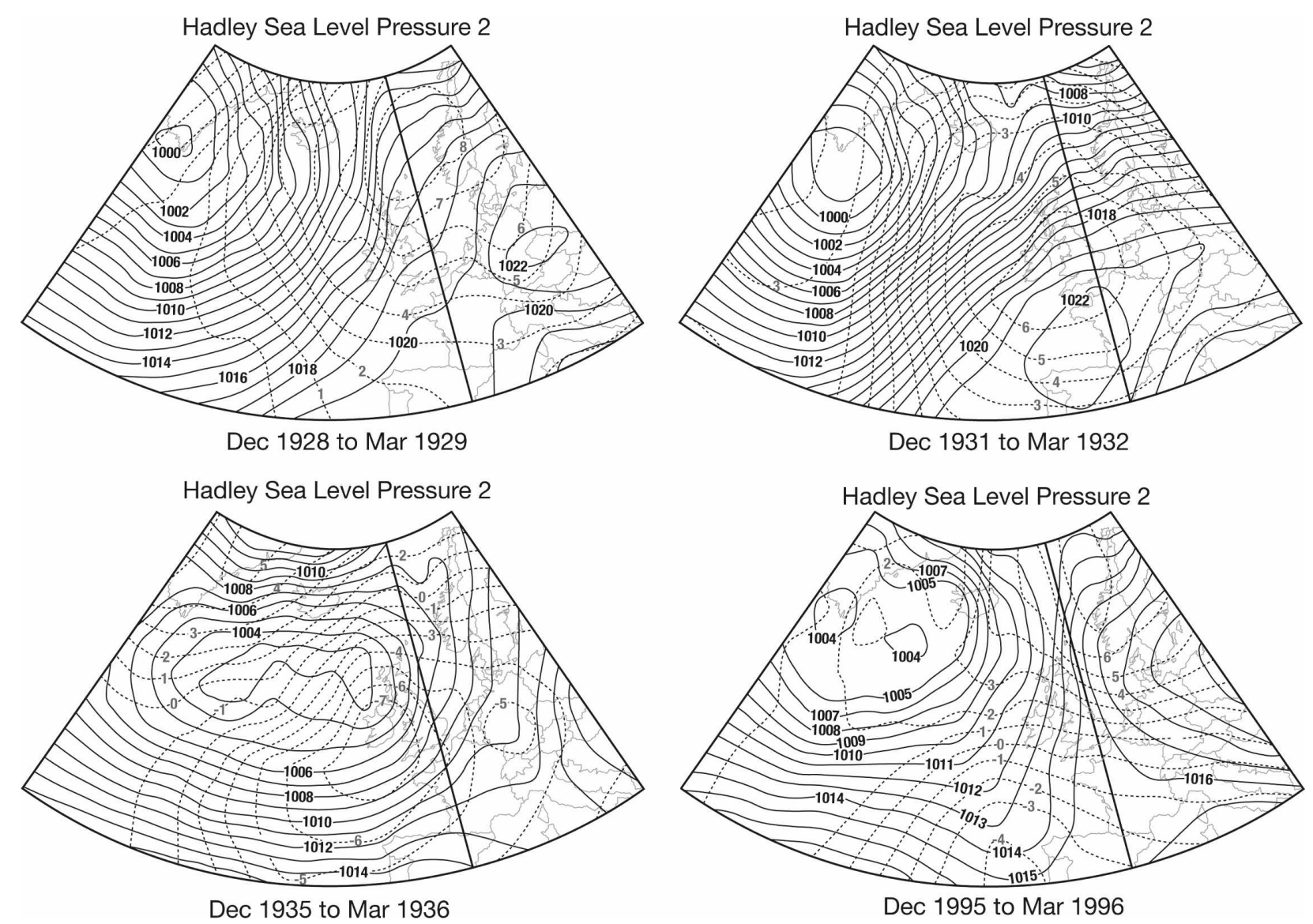

FIG. 11. (Continued)

Searson 2000), the dp(abs) 24 was only $1.9 \mathrm{hPa}$. The $\mathrm{dp}(\mathrm{abs}) 24$ analysis will not, therefore, necessarily be influenced by, or capture, individual fast-moving storms. The latter are better resolved through $\mathrm{dp}(\mathrm{abs}) 3$ (3-hourly absolute pressure variation) extreme-event analysis along the lines of Alexander et al. (2005), but the trade-off is a shorter time frame-typically the last 50 to $100 \mathrm{yr}$ - as barometer readings have become more frequent.

\section{Discussion and conclusions}

The main purpose of this study was to extend the $\mathrm{dp}(\mathrm{abs}) 24$ technique, initially applied to SW Icelandic pressure datasets by Jónsson and Hanna (2007). It has been extended to readily available WASA stationpressure datasets (here updated) and newly available daily pressure data for a well-distributed network of long-running meteorological stations at various locations in northwest Europe and the northern North Atlantic. We have shown that the relationship between long-term (seasonal/annual average) dp(abs)24 and wind speed holds for all sites studied and is stronger in winter than annually. However, we have also seen that $\mathrm{dp}(\mathrm{abs}) 24$ does not always well capture high-frequency (subdiurnal) wind storms. We have demonstrated high spatial coherence between interannual fluctuations in $\mathrm{dp}(\mathrm{abs}) 24$ at stations separated by some hundreds of kilometers (e.g., Iceland and Scotland, and Ireland and Denmark); the relationship tends to be negative for stations located on opposite sides of the mean jetstream axis (e.g., Greenland and the Channel Islands). We have quantified variations and trends in $d p(a b s) 24$ with time, showing no significant overall long-term changes, except for SW Iceland. The latter is a special case as long-term changes may be due to changes in local conditions, namely, enhanced continentality due to much more severe sea ice conditions around Iceland during much of the nineteenth century compared with today (Jónsson and Hanna 2007). However, marked short-term changes are evident. Analysis of extreme $\mathrm{dp}(\mathrm{abs}) 24$ winter values shows no obvious clustering of recent years that could represent increased storminess linked with global warming. High values of $d p(a b s) 24$ 
in the winter of 1994/95 (which have since been succeeded by lower values) were preceded by almost equally high dp(abs) 24 in the winter of 1907 , for example. The winters of 1928/29 and 1931/32 stand out as having particularly low mean $\mathrm{dp}(\mathrm{abs}) 24$.

Our findings are much in line with those of previous studies that pick up a general increase in North Atlantic cyclonicity and storminess between the 1960s and 1990s (Bärring \& von Storch 2004; Chang et al. 2002; McCabe et al. 2001; Schmith et al. 1998), although this varies by region: for example, Alexander et al. (2005) using $\mathrm{dp}(\mathrm{abs}) 3$ found a tendency toward more (less) severe storms in the United Kingdom (Iceland) in the past few decades, and Smits et al. (2005) found no significant trend in storminess over the Netherlands from 19622002 based on the geostrophic (station pressure-data derived) wind speed record. Our results likewise agree with the smaller number of studies (analyzing sufficiently long data series) that do not find a sustained longer-term increase in storminess since the nineteenth century (Alexandersson et al. 1998; Bärring \& von Storch 2004; WASA Group 1998). This perhaps lends a cautionary note to those who suggest that anthropogenic greenhouse warming probably results in enhanced extratropical storminess (e.g., Kaas and Anderson 1999), as this is indicated neither by our own nor existing published observational results for the northeast Atlantic for the last $\sim 150 \mathrm{yr}$.

The results of this study will be useful in at least two respects. The first is by extending the spatial and temporal coverage of the instrumental historical record of European and North Atlantic storminess, so placing the results of locally based studies such as Bärring and von Storch (2004) in a wider geographic and meteorological context. The second is by using our new dp(abs) 24 records to feed into and/or validate models of changing mid- to high-latitude storminess under climate change scenarios. For example, Singarayer et al. (2006) simulated intensified midlatitude storm tracks and increased winter precipitation over western and southern Europe in response to the widely projected reduction of Arctic sea ice by 2100 . Bengtsson et al. (2006) suggest a likely future poleward shift and intensification of the Atlantic storm track north of the United Kingdom, while Finnis et al. (2007) found few significant changes in storm tracks or intensity, and Jiang and Perrie (2007) found slightly poleward-shifted storm tracks but only marginal changes in severity. These examples serve to illustrate that in general, global climate model (GCM) projections of changes in the NAO and North Atlantic storminess vary widely and remain unreliable (Meehl et al. 2007). Therefore, the models are in need of further refinement and need to be checked against an im- proved observational record. The derivation of a centennial time scale, spatially distributed dp(abs) 24 series from a set of reliable observations-and for more recent years from gridded pressure datasets and GCMswill enable model-data $\mathrm{dp}(\mathrm{abs}) 24$ comparisons with twentieth-century model runs. The result will be a useful novel test of how realistically the GCMs simulate current climate variability and therefore their ability to realistically predict future climate change.

To help achieve the above aims, and having reflected on our results, we would like to make an appeal for more widespread international availability of long-term daily (or subdaily) barometric pressure data with appropriate metadata. Such pressure data are not as readily available as temperature and precipitation datasets, yet they are equally important in studying climate variability and change and, potentially, in attribution and detection studies of global warming.

Finally, in addition to providing an important data legacy and useful inferences about climatic variability and change, we suggest that the research results presented in this paper will have practical benefits: for example, our new $\mathrm{dp}(\mathrm{abs}) 24$ datasets are anticipated to be of interest to the insurance industry as they may feed into an improved risk assessment of storminess.

Acknowledgments. We thank the Armagh Observatory/John Butler/Ana García-Suárez, and Martin Crozier/Guernsey Meteorological Department for barometric pressure data/checking, the DMI for wind speed data, J. Jensen (DMI) for DMI wind speed metadata, and Paul Coles of the Department of Geography and Cartography Service of the University of Sheffield for drawing and reworking figures. NAOI data were obtained from the Web sites of J. Hurrell and the Climatic Research Unit. Edward Hanna thanks Grant Bigg and Julie Jones for useful background discussions, and David Parker made useful comments on the manuscript. Rob Allan was supported by the Met Office Hadley Centre's Integrated Climate Programme for the Ministry of Defence and the Department for Environment, Food and Rural Affairs (DEFRA), and this paper is U.K. Crown Copyright.

\section{REFERENCES}

Alexander, L. V., S. F. B. Tett, and T. Jónsson, 2005: Recent observed changes in severe storms over the United Kingdom and Iceland. Geophys. Res. Lett., 32, L13704, doi:10.1029/ 2005 GL022371.

Alexandersson, H., 1986: A homogeneity test applied to precipitation data. J. Climatol., 6, 661-675.

, T. Schmith, K. Iden, and H. Tuomenvirta, 1998: Long-term variations of the storm climate over NW Europe. Global Atmos. Ocean Syst., 6, 97-120. 
- , H. Tuomenvirta, T. Schmith, and K. Iden, 2000: Trends of storms in NW Europe derived from an updated pressure data set. Climate Res., 14, 71-73.

Allan, R., S. Tett, and L. Alexander, 2008: Fluctuations in autumn-winter severe storms over the British Isles: 1920 to present. Int. J. Climatol., doi:10.1002.joc.1765, in press.

Ansell, T. J., and Coauthors, 2006: Daily mean sea level pressure reconstructions for the European-North Atlantic region for the period 1850-2003. J. Climate, 19, 2717-2742.

Bahr, H., 1911: Die interdiurne Veränderlichkeit des Luftdruckes (in German). Meteor. Z., 28, 497-502.

Bärring, L., and H. von Storch, 2004: Scandinavian storminess since about 1800. Geophys. Res. Lett., 31, L20202, doi:10.1029/2004GL020441.

Barry, R. G., and R. J. Chorley, 2003: Atmosphere, Weather, and Climate. 8th ed. Routledge, 421 pp.

Bayer, K., 1965: Dlouhodobe variace v tlakovém poli nad Evropu [Langfristige Variationem im Druckfeld in Europa (Longterm variability of the pressure field in Europe; in Czech)]. Meteor. Zpravy, 18, 167-169.

Bengtsson, L., K. I. Hodges, and E. Roeckner, 2006: Storm tracks and climate change. J. Climate, 19, 3518-3543.

Berger, E., 1961: Siebenjährige Mittelkarten der interdiurnen Veränderlichkeit des Luftdruckes am Boden: 1951-1957 (Seven-year average maps of the interdiurnal variability of the air pressure at ground level over the area of North America to the North Atlantic to Eurasia for the months of January and July 1951-1957). Meteorologische Abhandlungen Band XIV/Heft 5, Institut für Meteorologie und Geophysik der Freien Universität Berlin, Verlag von Dietrich Reimer, 28 pp.

Bromirski, P. D., R. E. Flick, and D. R. Cayan, 2003: Storminess variability along the California coast: 1858-2000. J. Climate, 16, 982-993.

Burroughs, W. J., 2003: Weather Cycles Real or Imaginary? 2nd ed. Cambridge University Press, 23-25 and Appendix A.6.

Cappelen, J., and S. Rosenørn, Eds., 2007: Storms in Denmark from 1891. Danish Meteorological Institute, 4 pp. [Available online at http://www.dmi.dk/dmi/storme-2.pdf.]

_, E. Vaarby Laursen, and C. Kern-Hansen, 2007: DMI Daily Climate Data Collection 1873-2006, Denmark, The Faroe Islands and Greenland-Including Air Pressure Observations 1874-2006 (WASA Data Sets). Danish Meteorological Institute Tech. Rep. 07-07, DMI, 41 pp. [Available online at http://www.dmi.dk/dmi/tr07-07.pdf (report) and http:// www.dmi.dk/dmi/tr07-07_data.zip (data).]

Chang, E. K. M., and Y. Fu, 2002: Interdecadal variations in Northern Hemisphere winter storm track intensity. J. Climate, 15, 642-658.

- S. Lee, and K. L. Swanson, 2002: Storm track dynamics. $J$. Climate, 15, 2163-2183.

Cornes, R., 2008: The barometer measurements of the Royal Society of London: 1774-1842. Weather, 63, 230-235.

Dawson, A., I. Elliott, S. Noone, K. Hickey, P. Wadhams, and I. Foster, 2004: Historical storminess and climate 'see-saws' in the North Atlantic region. Mar. Geol., 210, 247-259.

de Groot, M., 1994: Meteorology and climatology at Armagh Observatory, 1790-1990. Observatories and Climatological Research, Occasional Publication 29, B. D., Giles, and J. M. Kenworthy, Eds., Department of Geography, University of Durham, 50-57.

Dunlop, S., 2001: A Dictionary of Weather. Oxford University Press, $266 \mathrm{pp}$.
Evjen, S., 1927: Untersuchung der barometrischen "Unruhe" in Vardö. Meteor. Z., 44, 472-473.

Finnis, J., M. M. Holland, M. C. Serreze, and J. J. Cassano, 2007: Response of Northern Hemisphere extratropical cyclone activity and associated precipitation to climate change, as represented by the Community Climate System Model. J. Geophys. Res., 112, G04S42, doi:10.1029/2006JG000286.

Flocchini, G., and C. Palau, 1987: Interdiurnal atmospheric pressure differences in Genoa, Italy. Meteor. Z., 37, 253-256.

Hanna, E., T. Jónsson, J. Ólafsson, and H. Valdimarsson, 2006: Icelandic coastal sea surface temperature records constructed: Putting the pulse on air-sea-climate interactions in the northern North Atlantic. Part 1: Comparison with HadISST1 open-ocean surface temperatures and preliminary analysis of long-term patterns and anomalies of SSTs around Iceland. J. Climate, 19, 5652-5666.

Haylock, M. R., P. D. Jones, R. J. Allan, and T. J. Ansell, 2007: Decadal changes in 1870-2004 Northern Hemisphere winter sea level pressure variability and its relationship with surface temperature. J. Geophys. Res., 112, D11103, doi:10.1029/ 2006JD007291.

Hickey, K. R., 2003: The storminess record from Armagh Observatory, Northern Ireland, 1796-1999. Weather, 58, 28-35.

, 2008: The hourly gale record from Valentia Observatory, SW Ireland, 1900-2006. Climatic Change, in press.

HMSO, 1982: Observer's Handbook. 4th ed. Met Office 933, Her Majesty's Stationary Office, London, United Kingdom, 220 pp.

Hurrell, J. W., 1995: Decadal trends in the North Atlantic Oscillation and relationships to regional temperature and precipitation. Science, 269, 676-679.

_, Y. Kushnir, G. Ottersen, and M. Visbeck, 2003: An overview of the North Atlantic Oscillation. The North Atlantic Oscillation: Climatic Significance and Environmental Impact, Geophys. Monogr., Vol. 134, Amer. Geophys. Union, 1-36.

Jiang, J., and W. Perrie, 2007: The impacts of climate change on autumn North Atlantic midlatitude cyclones. J. Climate, 20, 1174-1187.

Jones, P. D., T. Jónsson, and D. Wheeler, 1997: Extension to the North Atlantic Oscillation using early instrumental pressure observations from Gibraltar and South-West Iceland. Int. J. Climatol., 17, 1433-1450.

- E. B. Horton, C. K. Folland, M. Hulme, D. E. Parker, and T. A. Basnett, 1999: The use of indices to identify changes in climatic extremes. Climatic Change, 42, 131-149.

—, T. J. Osborn, and K. R. Briffa, 2003: Pressure-based measures of the North Atlantic Oscillation (NAO): A comparison and an assessment of changes in the strength of the NAO and in its influence on surface climate parameters. The North Atlantic Oscillation: Climatic Significance and Environmental Impact, Geophys. Monogr., Vol. 134, Amer. Geophys. Union, $51-62$.

Jónsson, T., and E. Hanna, 2007: A new day-to-day pressure variability index as a proxy of Icelandic storminess and complement to the North Atlantic Oscillation index 1823-2005. Meteor. Z., 16, 25-36, doi:10.1127/0941-2948/2007/0177.

Kaas, E., and U. Anderson, 1999: Scenarios for extra-tropical storm and wave activity: Methodologies and results. ECLAT-2 Rep. 3, KNMI, 24 pp.

Kämtz, L. F., 1832: Lehrbuch der Meteorologie. Vol. II. Leipzig, 305-308.

Kingston, D. G., D. M. Lawler, and G. R. McGregor, 2006: Linkages between atmospheric circulation, climate and stream- 
flow in the northern North Atlantic: Research prospects Prog. Phys. Geogr., 30, 143-174.

Kistler, R., and Coauthors, 2001: The NCEP-NCAR 50-year reanalysis: Monthly means CD-ROM and documentation. Bull. Amer. Meteor. Soc., 82, 247-268.

Klein, W. H., 1951: A hemispheric study of daily pressure variability at sea level and aloft. J. Meteor., 8, 332-346.

Lamb, H. H., 1972: Climate Present, Past and Future. Vol. 1. Methuen \& Co Ltd., 613 pp.

— 1991: Historic Storms of the North Sea, British Isles, and Northwest Europe., Cambridge University Press, 204 pp.

Landsberg, H. E., 1966: Interdiurnal variability of pressure and temperature in the conterminous United States. U.S. Department of Commerce Tech. Paper 56, 53 pp.

Le Blancq, F. W., 1988: A century of severe storms in Jersey. Ann. Bull. Soc. Jersiaise, 24, 519-525.

— , and J. A. Searson, 2000: The 1999 Boxing Day low-Some remarkable pressure tendencies. Weather, 55, 250-251.

Matulla, C., W. Schoener, H. Alexandersson, H. von Storch, and X. L. Wang, 2007: European storminess: Late 19th century to present. Climate Dyn., 31 (2-3), 125-130.

McCabe, G. J., M. P. Clark, and M. C. Serreze, 2001: Trends in Northern Hemisphere surface cyclone frequency and intensity. J. Climate, 14, 2763.

Meehl, G. A., and Coauthors, 2007: Global climate projections. Climate Change 2007: The Physical Science Basis, S. Solomon et al., Eds., Cambridge University Press, 747-845.

Osborn, T. J., 2006: Recent variations in the winter North Atlantic Oscillation. Weather, 61, 353-355.

Pedersen, 1845: Undersögelse over barometrets daglige middeloscillation paa Island. Oversigt over Det Kongelige Danske Videnskabernes Selskabs Forhandlinger (An investigation into the daily average barometric oscillation in Iceland), Danish Scientific Society, 65-69.

Polyakova, E. I., A. G. Journel, I. V. Polyakov, and U. S. Bhatt, 2006: Changing relationship between the North Atlantic Oscillation and key North Atlantic climate parameters. Geophys. Res. Lett., 33, L03711, doi:10.1029/2005GL024573.

Putins, P., 1962: Correlation between pressure changes aloft and at the surface in the Greenland area, and some aspects of the "steering" problem. Archiv Für Meteorologie, Geophysik und Bioklimatologie Serie A Meteorologie und Geophysik, W. Mörikofer, and F. Steinhauser, Eds., Springer-Verlag, 218240.

Rogers, J. C., 1997: North Atlantic storm track variability and its association to the North Atlantic Oscillation and climatic variability of northern Europe. J. Climate, 10, 1635-1647.
Schmith, T., H. Alexandersson, K. Iden, and H. Tuomenvirta, 1997: North Atlantic-European Pressure Observations 18681995 (WASA dataset version 1.0). Danish Meteorological Institute Tech. Rep. 97-3, DMI, 14 pp. [Available online at http://www.dmi.dk/dmi/tr97-3.pdf (report) and http://www. dmi.dk/dmi/data97-3.zip (data).]

—, E. Kaas, and T.-S. Li, 1998: Northeast Atlantic winter storminess 1875-1995 re-analysed. Climate Dyn., 14, 529-536.

Singarayer, J. S., J. L. Bamber, and P. J. Valdes, 2006: Twentyfirst-century climate impacts from a declining Arctic sea ice cover. J. Climate, 19, 1109-1125.

Smits, A., A. M. G. Klein Tank, and G. P. Können, 2005: Trends in storminess over the Netherlands, 1962-2002. Int. J. Climatol., 25, 1331-1344.

Travnicek, F., 1928: Der säkulare Gang der interdiurnen Veränderlichkeit des Luftdrucks und ihrer Abnahme mit der Höhe nach bestimmung von 56 Jahren für Salzburg und 40 Jahren für Sonnblick. Meteor. Z., 45, 299-302.

Trenberth, K. E., and Coauthors, 2007: Observations: Surface and atmospheric climate change. Climate Change 2007: The Physical Science Basis, S. Solomon et al., Eds., Cambridge University Press, 235-336.

Tyrrell, J. G., and K. Hickey, 1991: A flood chronology for Cork City and its climatological background. Irel. Geogr., 24, 8190.

Uppala, S. M., and Coauthors, 2005: The ERA-40 re-analysis. Quart. J. Roy. Meteor. Soc., 131, 2961-3012, doi:10.1256/ qj.04.176.

Vinther, B. M., K. K. Andersen, A. W. Hansen, T. Schmith, and P. D. Jones, 2003: Improving the Gibraltar/Reykjavik NAO index. Geophys. Res. Lett., 30, 2222, doi:10.1029/ 2003GL018220.

von Storch, H., and R. Weisse, 2008: Regional storm climate and related marine hazards in the Northeast Atlantic. Climate Extremes and Society, H. F. Diaz and R. J. Murnane, Eds., Cambridge University Press, 54-73.

Wang, X. L. L., V. R. Swail, and F. W. Zwiers, 2006: Climatology and changes of extratropical storm tracks and cyclone activity: Comparison of ERA-40 with NCEP/NCAR reanalysis for 1958-2001. J. Climate, 19, 3145-3166.

WASA Group, 1998: Changing waves and storms in the northeast Atlantic? Bull. Amer. Meteor. Soc., 79, 741-760.

Zveryaev, I. I., 1999: Decadal and longer changes of the winter sea level pressure fields and related synoptic activity over the North Atlantic. Int. J. Climatol., 19, 1177-1185. 